\title{
The increasing importance of atmospheric demand for ecosystem water and carbon fluxes
}

Kimberly A. Novick ${ }^{1, *}$, Darren L. Ficklin², Paul C. Stoy ${ }^{3}$, Christopher A. Williams ${ }^{4}$, Gil Bohrer $^{5}$, A. Christopher Oishi ${ }^{6}$, Shirley A. Papuga ${ }^{7}$, Peter D. Blanken ${ }^{8}$, Asko Noormets ${ }^{9}$, Benjamin Sulman ${ }^{10}$, Russell L. Scott ${ }^{11}$, Lixin Wang ${ }^{12}$, and Richard P. Phillips ${ }^{13}$

1,* Indiana University, School of Public and Environmental Affairs, Bloomington, IN, 47405, USA.

${ }^{2}$ Indiana University, Department of Geography, Bloomington, IN, 47405, USA.

${ }^{3}$ Montana State University, Department of Land Resources and Environmental Sciences, Bozeman, MT 59717, USA

${ }^{4}$ Clark University, Graduate School of Geography, Worcester, MA, 01610, USA

${ }^{5}$ The Ohio State University, Department of Civil, Environmental \& Geodetic Engineering, Columbus, $\mathrm{OH}, 43210$, USA

${ }^{6}$ USDA Forest Service, Southern Research Station, Coweeta Hydrologic Laboratory, Otto, NC 28763, USA

${ }^{7}$ University of Arizona, School of Natural Resources and the Environment, Tucson, AZ, 85721, USA

${ }^{8}$ University of Colorado, Department of Geography, Boulder, CO 80309-0260, USA

${ }^{9}$ North Carolina State University, Department of Forestry and Natural Resources, Raleigh, NC 27695, USA

${ }^{10}$ Princeton University, Department of Geosciences, Princeton, NJ 08544, USA

${ }^{11}$ Russell L. Scott, Southwest Watershed Research Center, USDA-ARS, Tucson, AZ, USA

${ }^{12}$ Indiana University-Purdue University Indianapolis (IUPUI), Department of Earth Sciences, Indianapolis, IN 46202, USA

${ }^{13}$ Indiana University, Department of Biology, Bloomington, IN, 47405, USA. 
Soil moisture supply and atmospheric water demand independently limit - and

29 profoundly affect - ecosystem productivity and vegetation water use during periods of

30 hydrologic stress ${ }^{1,2,3,4}$. Disentangling the impact of these two drivers on ecosystem carbon and

31 water fluxes is difficult because they are often correlated, and experimental tools for

32 manipulating atmospheric demand in the field are lacking. Consequently, the role of atmospheric

33 demand is often not adequately factored into experiments or represented in models ${ }^{5,6,7}$. Here we

34 show that atmospheric demand limits surface conductance and evapotranspiration to a greater

35 extent than soil moisture in many biomes, including mesic forests that are of particular

36 importance to the terrestrial carbon $\operatorname{sink}^{8,9}$. Further, using projections from ten general

37 circulation models, we show that climate change will increase the importance of atmospheric

38 constraints to carbon and water fluxes in all ecosystems. Consequently, atmospheric demand will

39 become increasingly important for vegetation function, accounting for $>70 \%$ of growing season

40 limitation to surface conductance in mesic temperate forests. Our results suggest that failure to

41 consider the limiting role of atmospheric demand in experimental designs, simulation models,

42 and land management strategies will lead to incorrect projections of ecosystem responses to

43 future climate conditions.

Ecosystem moisture stress is often characterized by changes in soil water availability ${ }^{10,11}$.

46 Declining soil moisture impedes the movement of water to evaporating sites at the soil or leaf

47 surface $\mathrm{e}^{12}$ and reduces the surface conductance to water vapor $\left(G_{\mathrm{S}}\right)$ - a key determinant of carbon

48 and water cycling - and thereby evapotranspiration (ET). However, atmospheric demand for

49 water, which is directly related to the atmospheric vapor pressure deficit (VPD), also affects $G_{\mathrm{S}}$

50 and ET. Plants close their stomata to prevent excessive water loss when VPD is high ${ }^{13,14,15,16}$ and 
51 thus, increases in VPD during periods of hydrologic stress represent an independent constraint on

52 plant carbon uptake and water use in ecosystems.

While the plant physiological community has long recognized the critical role of VPD in determining plant functioning, VPD is often overlooked in many fields of hydrologic and climate

56 science. For example, precipitation manipulation experiments are frequently used to draw

57 conclusions about ecosystem response to drought stress, even though VPD is unaffected in these

58 experiments ${ }^{10}$. Some terrestrial ecosystem and ecohydrologic models do not permit stomatal

59 conductance to vary with atmospheric demand ${ }^{5,11}$. Many models designed to capture these

60 impacts rely on empirical parameterizations for soil moisture and VPD stress that promote

61 compensating effects and model equifinality ${ }^{5}$, and/or use relative humidity instead of VPD as the

62 primary driver, with significant consequences for projections of carbon uptake ${ }^{7}$. Furthermore,

63 while much attention has been focused on hydrologic cycle feedbacks driven by stomatal closure

64 under elevated $\mathrm{CO}_{2}{ }^{17,18,19}$, scarce attention has been paid to the potential for hydrologic cycle

65 feedbacks driven by stomatal closure under increasing VPD.

Looking to the future, it will become increasingly important to separately resolve VPD

68 and soil moisture effects on ecosystem functioning. VPD is highly sensitive to changes in air

69 temperature and is thus expected to rise globally in the future ${ }^{1,20}$. On the other hand, projected

70 changes in precipitation and soil moisture are less certain, more spatially variable, and smaller in

71 relative magnitude ${ }^{21}$. As a result, soil moisture and VPD will likely become more decoupled,

72 which could cause the ecological impacts of droughts to diverge even further from our present

73 understanding. As a consequence, models may over-predict the magnitude of carbon and water 
74 fluxes during periods of intermediate to high $V P D$, and management approaches that improve 75 soil moisture balance, including irrigation and forest thinning, may become less effective at 76 mitigating hydrologic stress.

77

$G_{S}=G_{S, r e f}(1-m \cdot \ln (V P D))$,

93 where the intercept parameter $G_{\mathrm{S} \text {,ref }}$ is a reference surface conductance rate $\left(\mathrm{mmol} \mathrm{m}^{-2} \mathrm{~s}^{-1}\right)$ at

$94 V P D=1(\mathrm{kPa})$. The parameter $G_{\text {S,ref }}$ is also sensitive to variations in radiation and temperature ${ }^{25}$,

$95{ }^{26}$, but omitting those dependencies does not bias the present analysis, as discussed in the 
supplementary information (hereafter the S.I.). The parameter $m$ describes the sensitivity of

97 surface conductance to VPD. If $G_{S}$ is dominated by stomatal conductance, then $m$ is expected to

98 be $c a .0 .6\left(\mathrm{mmol} \mathrm{m}^{-2} \mathrm{~s}^{-1} \mathrm{kPa}^{-1}\right)^{13}$. The parameter $m$ will decrease as the contribution of soil

99 conductance to $G_{S}$ increases, or in response to plant regulation of leaf water potential during

100 periods of hydrologic stress ${ }^{27}$. For sites in which limitations from VPD dominate $G_{s}$, there will

101 be little change in $G_{\mathrm{S} \text {,ref }}$ as soil moisture declines (Fig. 1b). In sites where soil moisture

102 limitations are important, $G_{\mathrm{S}, \mathrm{ref}}$ will decline as soil dries, and $m$ may concurrently decrease (Fig.

103 1c).

In each site, we sorted the surface conductance data into six bins delineated on the basis 105 of volumetric soil moisture $(\theta)$. Then, we determined the parameters of Eq. 1 within each soil 106 moisture bin by linear regression of the tower-derived $G_{s}$ with the observed VPD. We limited 107 the analysis to periods of relatively stationary leaf area and near-neutral or unstable atmospheric 108 conditions, as discussed in more detail in the SI. The data-driven, soil-moisture specific 109 parameterizations of Eq. 1 were then used to quantify the total and relative growing season 110 limitation to $G_{S}$ and $E T$ imposed by $\theta$ and $V P D$.

Across all sites and soil moisture conditions, the parameter $m$ was almost always greater 112 than zero, indicating stomatal limitation to $G_{\mathrm{S}}$ (Fig. 2a-d, e, g). The sensitivity parameter $m$ was 113 reduced at low $\theta$ in sites with intermediate and high DI (Fig. 2e), and in ecosystems with sparser 114 and shorter vegetation (Fig. 2g). In all but the very wettest sites with DI $<1$, the intercept 115 parameter $G_{\mathrm{s} \text {,ref }}$ declined with declining $\theta$, indicating soil moisture limitation to $G_{\mathrm{s}}$. These 116 declines were most pronounced in sparsely-vegetated ecosystems with DI > 4 (Fig. 2f,h). 

$G_{\mathrm{S}}$ (hereafter $\alpha_{\mathrm{VPD}: \mathrm{TOTAL}, G_{S}}$ ) was $>0.5$, on average, in wet and mesic sites (DI $\left.<2.5\right)$, indicating that $V P D$ was the dominant limiting driver to $G_{S}$ (Fig. 3a). Many of these mesic sites are forested ecosystems, where the mean $\alpha_{\mathrm{VPD}: \mathrm{TOTAL}, G_{S}}=0.61$ (range of 0.06 to 1.0 ). In contrast, $\alpha_{\mathrm{VPD}: \text { TOTAL, } G_{S}}$ was $<0.5$ in drier, typically non-forested sites where $\theta$ was more important to $G_{\mathrm{S}}$ 122 variability (Fig. 3a). These trends were driven by the fact that VPD limitations to $G_{\mathrm{S}}$ peaked in 123 intermediately wet sites (Fig. 3e) while soil moisture limitations to $G$ s tended to increase 124 monotonically across the gradient of dryness index (Fig. 3c). The ratio of VPD to total limitation 125 to $E T\left(\alpha_{\mathrm{VPD}: \mathrm{TOTAL}, E T}\right)$ was also $>0.5$ in relatively wet sites $(\mathrm{DI}<2.5)$, and $>0.70$ in forests, but 126 decreased in drier sites (Fig. 3b,d,f).

We observed considerable variability in the relative importance of VPD limitations among relatively mesic sites growing at similar DI. For example, soil moisture limitations tended 129 to be higher in short-statured ecosystems than in forests (Fig.3a) which may highlight the 130 importance of plant reliance on stored water or deep rooting systems in taller ecosystems ${ }^{6}$. Plant 131 water use strategy (e.g. isohydric or anisohydric) has also been identified as a factor determining 132 the sensitivity of stomatal conductance to $V P D^{1,27,28}$. Accounting for all these sources of 133 variability was outside of the scope of this particular study, but should motivate future research. To understand whether predicted changes in climate have the potential to alter the 135 relative importance of $V P D$ versus soil moisture limitations to $G_{\mathrm{S}}$, we obtained projected future 136 meteorological times series from ten downscaled general circulation models (GCMs, see SI). 137 Increases in mean growing season $V P D$ were projected for every site (Fig. 4a,b). In contrast, and 138 consistent with other studies ${ }^{21}$, soil moisture was projected to increase at some sites but remained 
139 unchanged at others, with small overall changes relative to inter-model variability (Fig. 4a,b). As

140 a result, we predict that $V P D$ limitation to $G_{S}$ will increase under future climate scenarios in

141 most ecosystems, whereas the trends for future soil moisture limitation to Gs are mixed (Fig.

142 4c,d). Future VPD limitations are particularly important in forest ecosystems, where we project

143 the future $\alpha_{V P D: T O T A L}$ will exceed 0.7 on average. Interestingly, soil moisture limitations to ET

144 will also increase in nearly all sites (Fig. 4e,f), even though soil moisture limitations to Gs are

145 less consistent. This apparent paradox, which has been reported elsewhere ${ }^{3}$, reflects the fact that

146 the relationship between $E T$ and $G_{S}$ is hyperbolic (see Eq. S2 in the supplementary information),

147 and future ET is thus sensitive to changes in the variance or skewness of the $\theta$ distribution, even

148 if changes in the mean $\theta$ are small.

The climate projections are designed to isolate the impact of future changes in VPD and 150 soil moisture on $G_{\mathrm{S}}$ and $E T$. Stomatal conductance may be independently reduced in the future 151 by higher water use efficiency under elevated $\mathrm{CO}_{2}$, with relative reductions on the order of $c a$ $152 \sim 20 \%$ predicted by both modeling and experimental work ${ }^{17,18,19}$. Here, we report relative 153 reductions in $G_{\mathrm{S}}$ driven by rising VPD on the order of $10 \%$ in most forest ecosystems, which 154 would imply even greater relative reductions in canopy stomatal conductance since $G_{S}$ is 155 influenced by soil conductance, which is not sensitive to VPD. While VPD and $\mathrm{CO}_{2}$

156 concentrations are assumed to be independent drivers of stomatal conductance in theoretical

157 formulations ${ }^{17,19}$, the extent to which their effects on stomatal conductance are additive remains

158 an important topic for future work, which must also consider the confounding effects of 159 increasing leaf area index ${ }^{29}$. 
In summary, our results indicate that atmospheric constraints play a critical and

162 increasingly important role in controlling ecosystem fluxes of carbon and water. In the future,

163 higher VPD will increase the relative importance of $V P D$ in limiting $G_{\mathrm{S}}$ and $E T$ across the

164 biomes studied here, especially in mesic forest ecosystems which drive the terrestrial carbon

$165 \operatorname{sink}^{9}$. Consequently, conceptual and mathematical models that do not independently resolve

$166 V P D$ and soil moisture limitations will not adequately capture the magnitude of ecosystem

167 response to future hydrologic stress. Our results also have important implications for the

168 effective application of management approaches such as irrigation and thinning for alleviating

169 future drought stress. While these approaches improve the soil moisture balance ${ }^{30}$, unless applied

170 over large land areas, they likely have little effect on local VPD, which we project will become

171 the dominant limiting driver in many biomes.

172

173

174

175

176

177

178

179

180 
181 AUTHOR CONTRIBUTIONS: K.A.N. designed the study and methodology, with substantial 182 input from all co-authors, especially D.L.F., C.A.W., and R.P.P. D.L.F. obtained and processed 183 the future climate projections. K.A.N., G.B., S.A.P., P.D.B, A.N., B.S., R.L.S, R.P.P, and P.C.S. 184 contributed ecosystem flux data. All authors contributed to data analysis and interpretation. 185 K.A.N. and D.L.F. drafted the manuscript. All authors commented on and approved the final 186 manuscript.

187 Correspondence and request for materials should be directed to K.A.N.

188 COMPETING FINANCIAL INTERESTS: The authors declare no competing financial 189 interests.

190 ACKNOWLEDGEMENTS: We acknowledge the US Department of Energy for its support of 191 the Ameriflux Management Project administered by Lawrence Berkeley National Lab, and of the 192 Climate Model Diagnosis and Intercomparison Project. We thank the Ameriflux site teams for 193 sharing their data, and the individual climate modeling groups for sharing their model output. We 194 acknowledge the World Climate Research Programme’s Working Group on Coupled Modelling, 195 which is responsible for the Coupled Model Intercomparison Project (CMIP). KAN 196 acknowledges NSF grant DEB 1552747. PCS acknowledges National Science Foundation (NSF) 197 grants DEB 1552976 and EF 1241881. SAP acknowledges NSF grant EAR 125501. LW 198 acknowledges NSF grant EAR 155489. 
Figure 1: Conceptual framework. Panel (a) illustrates that while soil moisture and vapor

204 pressure deficit (VPD) are correlated at seasonal and monthly time scales, they are largely 205 decoupled at daily and hourly timescales. Data points show the mean correlation coefficient 206 across the 38 study sites. Thick bars show one standard deviation, and the thin bars show the 207 entire range of correlations. This separation at different scales in time permits us to disentangle

208 the role of VPD as compared to soil moisture on surface conductance $\left(G_{\mathrm{S}}\right)$. Panels (b) and (c) 209 illustrate predicted changes in this relationship between $G_{\mathrm{S}}$ and VPD as soil dries at a site where 210 VPD limitations dominate (b), and where soil moisture limitations dominate (c). The well211 watered reference conductance rate $\left(G_{S, r e f, w w}\right)$ is shown with black circles. Figure 2: How the relationship between surface conductance and vapor pressure deficit varies

214 with soil moisture. Panels (a-d) are illustrations of how the relationship between reference 215 surface conductance $\left(G_{S, r e f}\right)$ and vapor pressure deficit $(V P D)$ changes as soil moisture declines 216 in four (of 38) Ameriflux sites that span a range of dryness index (see SI for more details on 217 study sites). Panels (e-h) show the slope and intercept of Eq. 1 ( $m$ and $G_{S, r e f}$ ) as a function of soil 218 moisture content when data are pooled by dryness index (DI $=P E T_{P M} / P$, e and f) or plant 219 functional type (panels $g$ and $h$ ). Error bars show the standard error of the mean. 
221 Figure 3: Growing season limitations to $\boldsymbol{G}_{\mathrm{S}}$ and $\mathbf{E T}$ : The top row shows the ratio of VPD to

222 total limitations to growing $G_{S}\left(\alpha_{\mathrm{VPD}: \text { TOTAL, } G_{S}}\right.$, panel a) and ET $G_{S}\left(\alpha_{V P D: T O T A L, E T}\right.$, panel $\left.b\right)$. A

223 value of 1.0 indicates that soil moisture limitations are negligible. Other panels show the

224 magnitude of reductions in growing season surface conductance ( $G_{S}$, left column) and

225 evapotranspiration (ET, right column) imposed by soil moisture ( $\theta$, panels $c$ and $d$ ) and vapor

226 pressure deficit (VPD, panels e and f) across the range of dryness indices observed at 38

227 Ameriflux sites. Error bars show the $50^{\text {th }}$ percentile range in hourly $G_{S, r e f, w w}-G_{S}$ (for panels $c$

228 and e) and PET - ET (for panels $d$ and f). Shaded areas show the moving average across the

229 range of dryness index.

$231 \quad$ Figure 4: The projected shifts in key study variables from present to future climate conditions,

232 as indicated by the magnitude and direction of the arrows. Ovals show the range in growing

233 season averages of study variables emerging from the ten general circulation models. The

234 models predict global increases in VPD, with projected shifts in soil moisture content that are

235 smaller and less uniform across the study sites (panels a \& b). Limitations to ET and Gs are

236 shown here as relative quantities, normalized by the $G_{S, r e f, w w}$ and growing season average PET,

237 respectively. Sites located to the right of the 1:1 line shown in panels (c-f) experience relatively

238 greater limitation from VPD than soil moisture. Note that the axis range shifts from one panel to 239 the next. 


\section{REFERENCES}

241 1. McDowell NG, Allen CD. Darcy's law predicts widespread forest mortality under climate $242 \quad$ warming. Nature Climate Change 2015, 5(7): 669-672.

243

2. Williams AP, Allen CD, Macalady AK, Griffin D, Woodhouse CA, Meko DM, et al. Temperature as a potent driver of regional forest drought stress and tree mortality. Nature Clim Change 2013, 3(3): 292-297.

3. Jung M, Reichstein M, Ciais P, Seneviratne SI, Sheffield J, Goulden ML, et al. Recent decline in the global land evapotranspiration trend due to limited moisture supply. Nature 2010, 467(7318): 951-954.

4. Schaefer K, Schwalm CR, Williams C, Arain MA, Barr A, Chen JM, et al. A model-data comparison of gross primary productivity: Results from the North American Carbon Program site synthesis. Journal of Geophysical Research: Biogeosciences (2005-2012) 2012, 117(G3).

5. Bonan G, Williams M, Fisher R, Oleson K. Modeling stomatal conductance in the earth system: linking leaf water-use efficiency and water transport along the soil-plantatmosphere continuum. Geoscientific Model Development 2014, 7(5): 2193-2222.

6. Matheny AM, Bohrer G, Stoy PC, Baker IT, Black AT, Desai AR, et al. Characterizing the diurnal patterns of errors in the prediction of evapotranspiration by several landsurface models: An NACP analysis. Journal of Geophysical Research: Biogeosciences 2014, 119(7): 1458-1473.

7. Sato H, Kumagai T, Takahashi A, Katul GG. Effects of different representations of stomatal conductance response to humidity across the African continent under warmer CO2-enriched climate conditions. Journal of Geophysical Research: Biogeosciences 2015, 120(5): 979-988.

8. Peters W, Jacobson AR, Sweeney C, Andrews AE, Conway TJ, Masarie K, et al. An atmospheric perspective on North American carbon dioxide exchange: CarbonTracker. Proceedings of the National Academy of Sciences 2007, 104(48): 18925-18930.

9. Pan Y, Birdsey RA, Fang J, Houghton R, Kauppi PE, Kurz WA, et al. A large and persistent carbon sink in the world's forests. Science 2011, 333(6045): 988-993. 
10. Beier C, Beierkuhnlein C, Wohlgemuth T, Penuelas J, Emmett B, Körner C, et al. Precipitation manipulation experiments-challenges and recommendations for the future. Ecol Lett 2012, 15(8): 899-911.

11. Rodriguez-Iturbe I, Porporato A. Ecohydrology of water-controlled ecosystems - soil moisture and plant dynamics. Cambridge University Press: Cambridge, 2004.

12. Tyree MT, Sperry JS. Vulnerability of xylem to cavitation and embolism. Annual review of plant biology 1989, 40(1): 19-36.

13. Oren R, Sperry JS, Katul GG, Pataki DE, Ewers BE, Phillips N, et al. Survey and synthesis of intra- and interspecific variation in stomatal sensitivity to vapour pressure deficit. Plant Cell Environ 1999, 22(12): 1515-1526.

14. Cowan IR, Farquhar GD. Stomatal function in relation to leaf metabolism and environment. Symposia of the Society for Experimental Biology 1977, 31: 471-505.

15. McAdam SA, Brodribb TJ. The evolution of mechanisms driving the stomatal response to vapor pressure deficit. Plant physiology 2015, 167(3): 833-843.

16. Lendzion J, Leuschner C. Growth of European beech (Fagus sylvatica L.) saplings is limited by elevated atmospheric vapour pressure deficits. Forest Ecology and Management 2008, 256(4): 648-655.

17. Katul G, Manzoni S, Palmroth S, Oren R. A stomatal optimization theory to describe the effects of atmospheric $\mathrm{CO}_{2}$ on leaf photosynthesis and transpiration. Annals of Botany 2010, 105(3): 431-442.

18. Ainsworth EA, Rogers A. The response of photosynthesis and stomatal conductance to rising $\left[\mathrm{CO}_{2}\right]$ : mechanisms and environmental interactions. Plant, cell \& environment 2007, 30(3): 258-270.

19. Medlyn BE, Duursma RA, Eamus D, Ellsworth DS, Prentice IC, Barton CVM, et al. Reconciling the optimal and empirical approaches to modelling stomatal conductance. Global Change Biology 2011, 17(6): 2134-2144.

20. Greve P, Orlowsky B, Mueller B, Sheffield J, Reichstein M, Seneviratne SI. Global assessment of trends in wetting and drying over land. Nature Geoscience 2014, 7(10): 716-721. 
21. Burke EJ, Brown SJ. Evaluating uncertainties in the projection of future drought. $J$ Hydrometeorol 2008, 9(2): 292-299.

22. Budyko MI. Climate and Life. Academic Press: New York, 1974.

322

323

324

325

326

327

23. Williams CA, Reichstein M, Buchmann N, Baldocchi D, Beer C, Schwalm C, et al. Climate and vegetation controls on the surface water balance: Synthesis of evapotranspiration measured across a global network of flux towers. Water Resources Research 2012, 48(6).

24. Monteith JL. Evaporation and environment. In: Fogg BD (ed). The State and Movement of water in Living Organisms, Symposium of the Society of Experimental Biology, vol. 19. Cambridge University Press: Cambridge, 1965, pp 205-234.

25. Granier A, Loustau D, Breda N. A generic model of forest canopy conductance dependent on climate, soil water availability and leaf area index. Annals of Forest Science 2000, 57(8): 755-765.

26. Jarvis $P$. The interpretation of the variations in leaf water potential and stomatal conductance found in canopies in the field. Philosophical Transactions of the Royal Society of London B: Biological Sciences 1976, 273(927): 593-610.

27. Novick KA, Miniat CF, Vose JM. Drought limitations to leaf-level gas exchange: results from a model linking stomatal optimization and cohesion-tension theory. Plant, cell \& environment 2016.

28. Ruehr NK, Martin JG, Law BE. Effects of water availability on carbon and water exchange in a young ponderosa pine forest: Above-and belowground responses. Agricultural and forest meteorology 2012, 164: 136-148.

29. Zhu Z, Piao S, Myneni RB, Huang M, Zeng Z, Canadell JG, et al. Greening of the Earth and its drivers. Nature Climate Change 2016.

30. Bréda N, Granier A, Aussenac G. Effects of thinning on soil and tree water relations, transpiration and growth in an oak forest (Quercus petraea (Matt.) Liebl.). Tree physiology 1995, 15(5): 295-306. 
356 
Figure 1
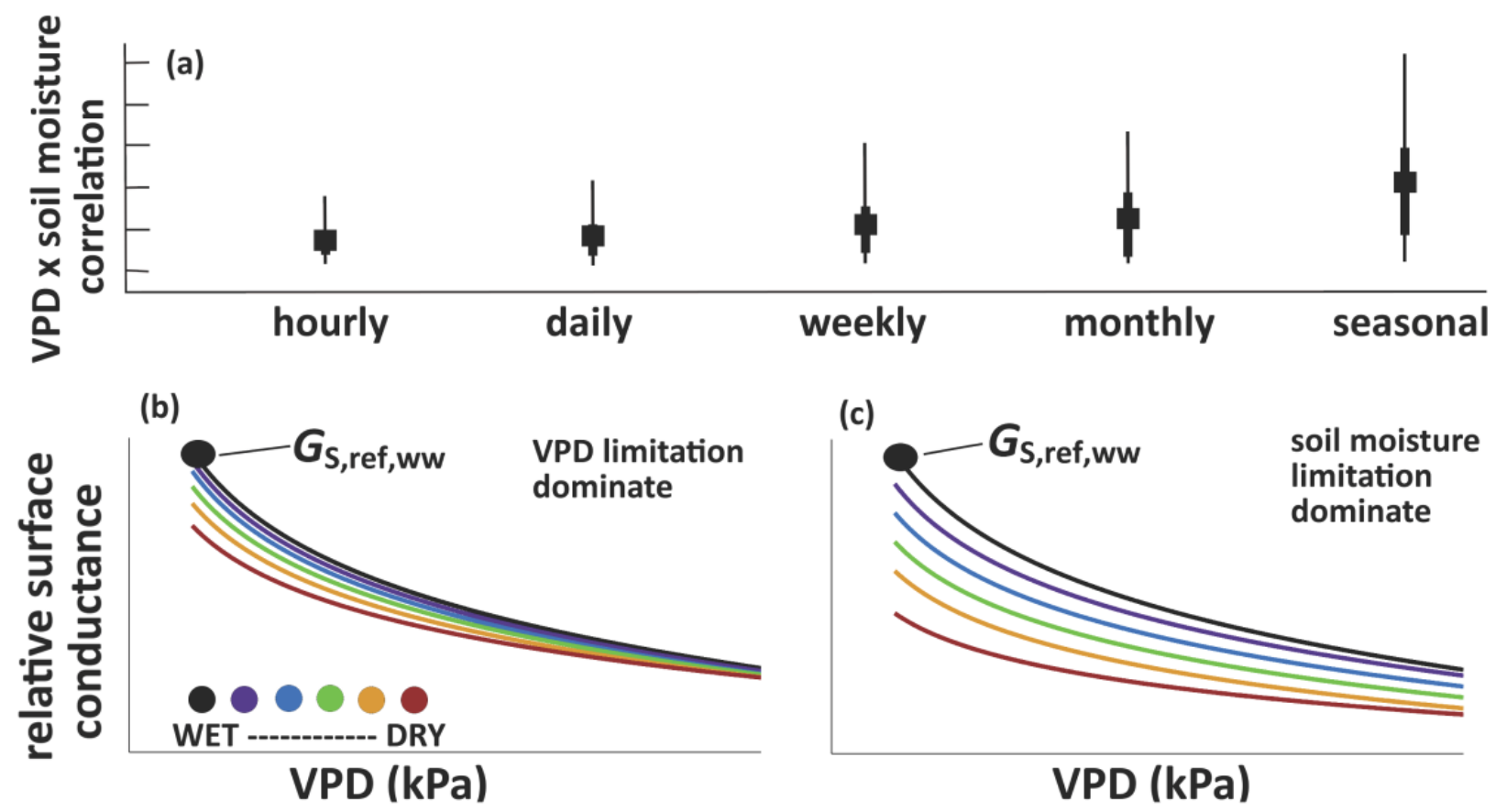
Figure 2
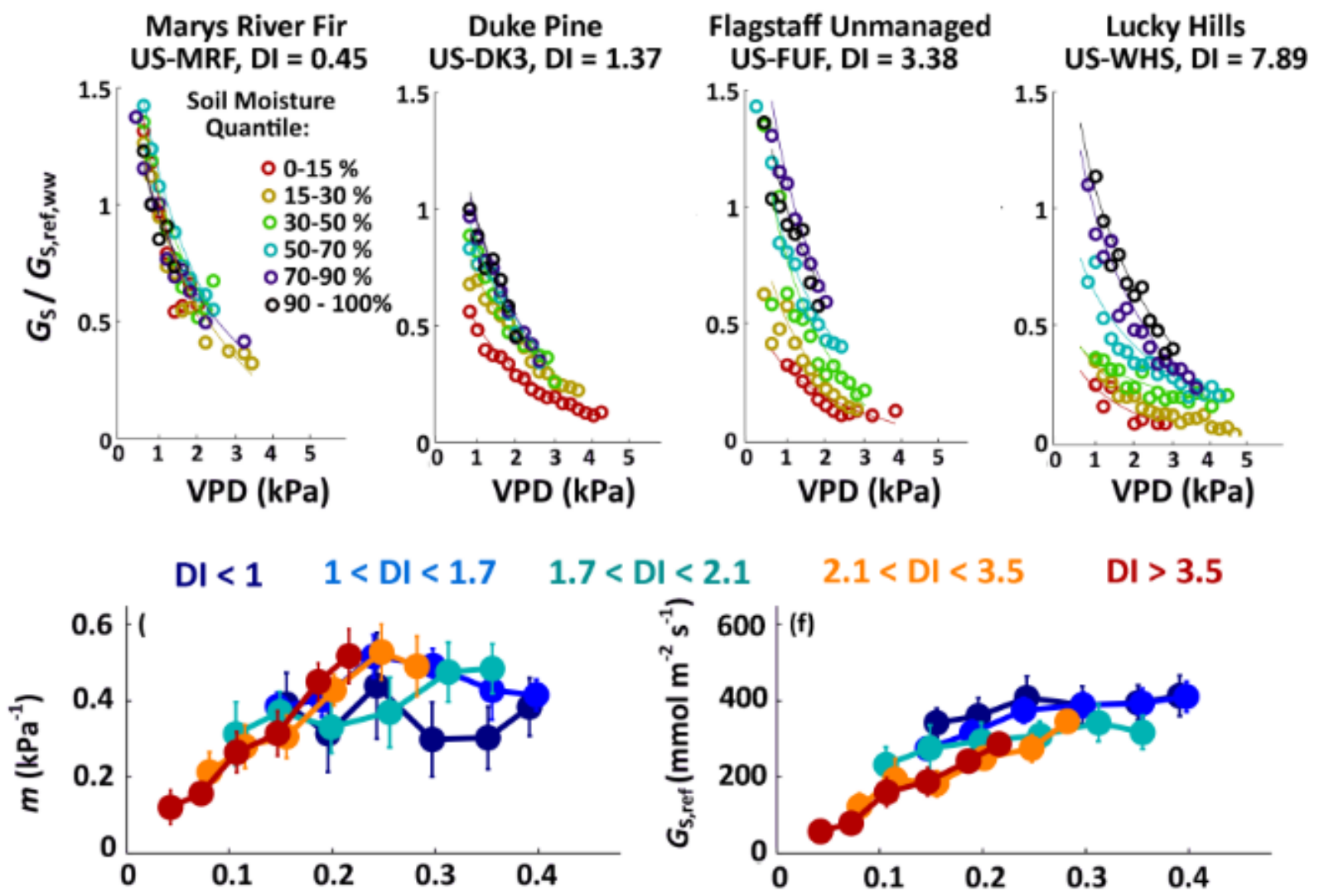

Evergreen Needleleaf Forest Deciduous Broadleaf Forest

Croplands Grasslands Savannahs \& Shrublands
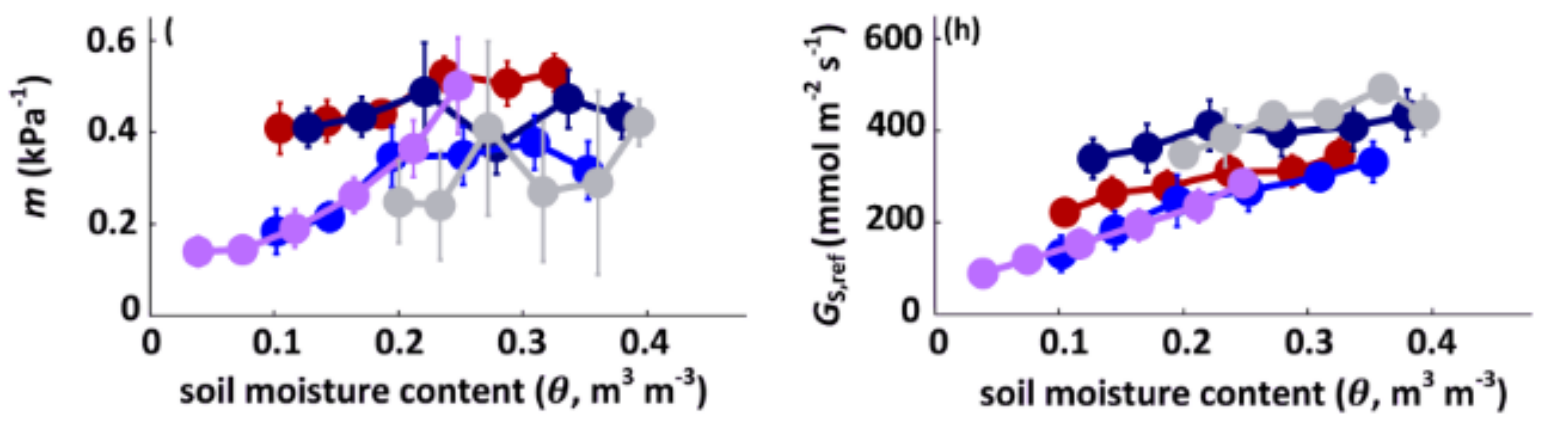
Figure 3

\section{ratio of VPD to total (i.e. VPD $+\boldsymbol{\theta}$ ) limitation}
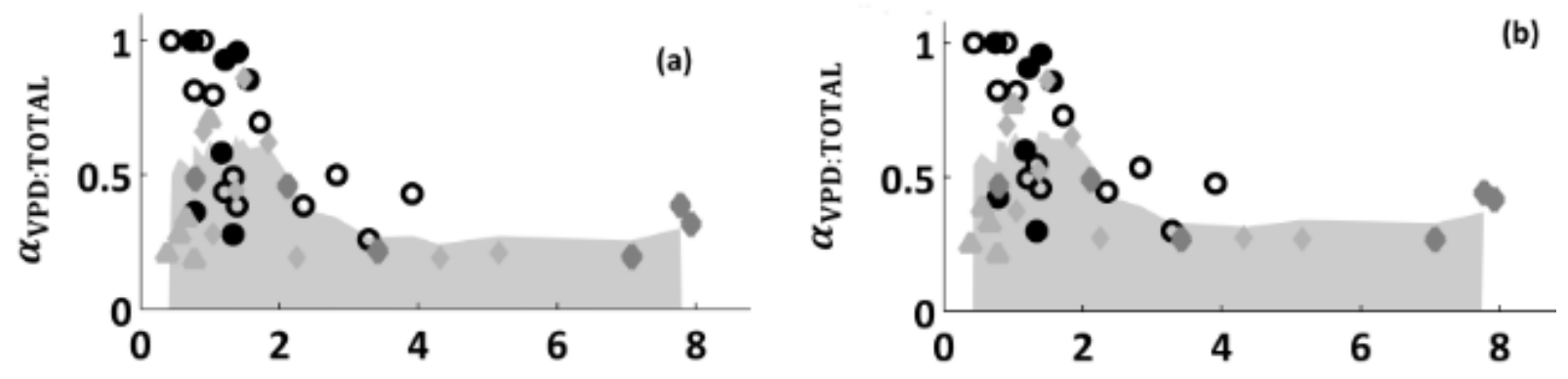

soil moisture $(\theta)$ limitation
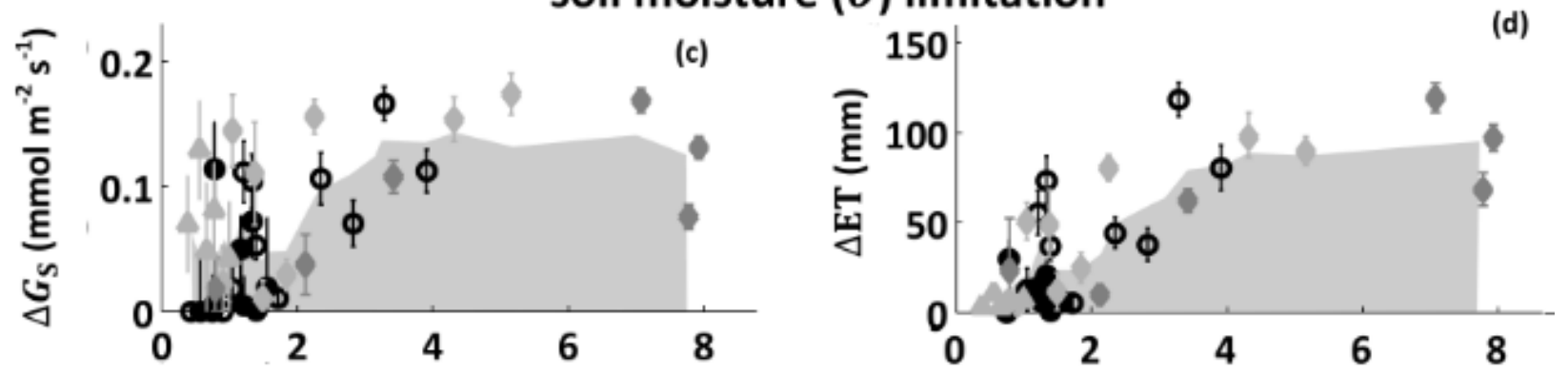

VPD limitation
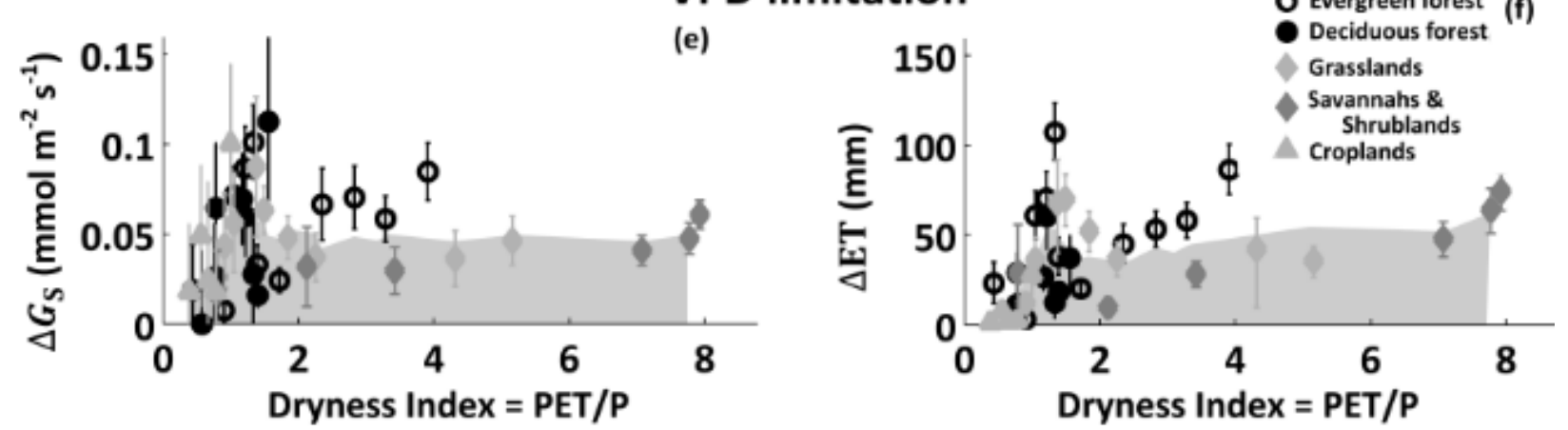
Figure 4
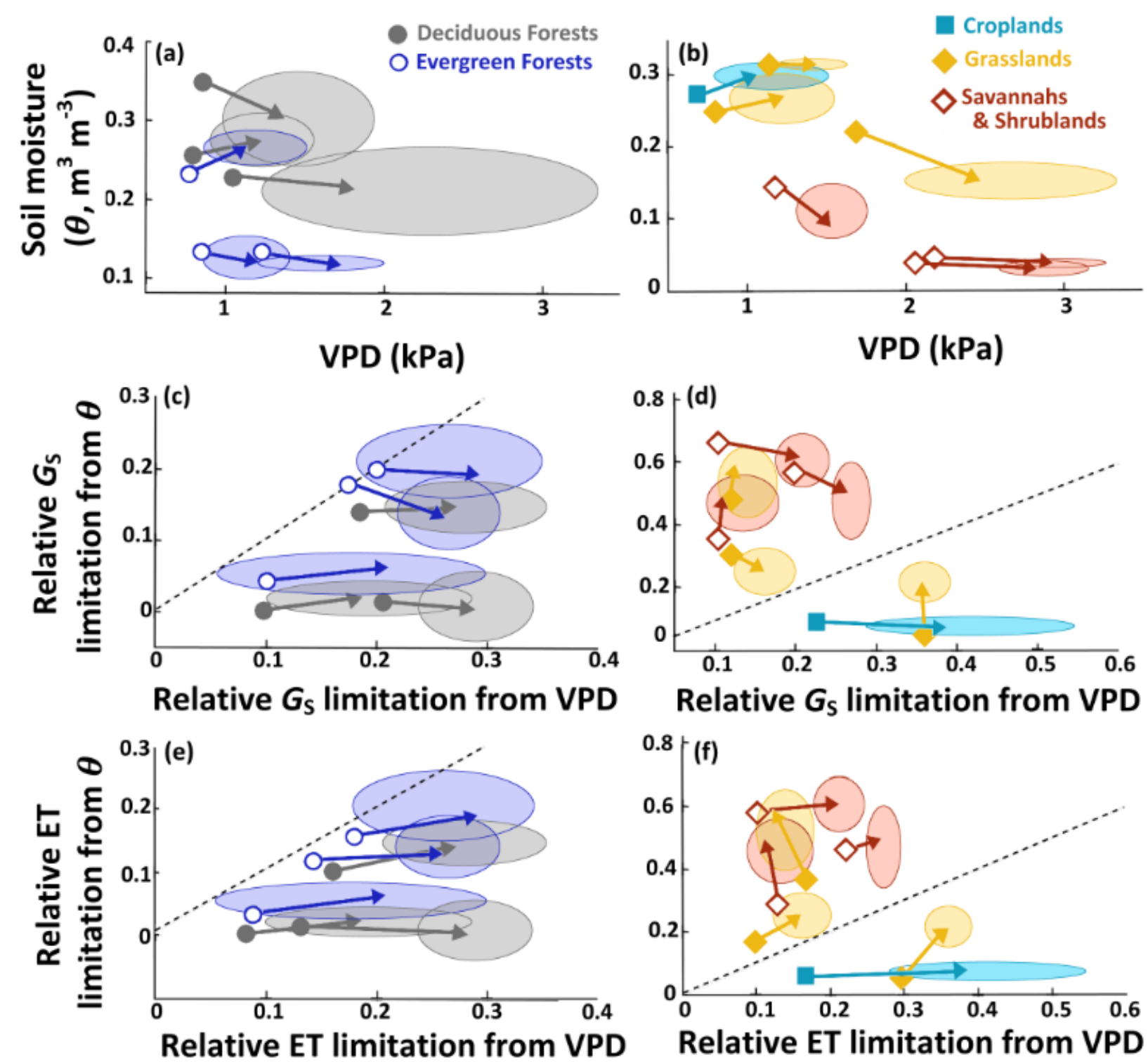


\section{Supplementary Information and Discussion}

\section{Contents:}

Section S1: Ameriflux data quality control and filtering 2

$\begin{array}{ll}\text { Section S2: Selecting the model for potential evapotranspiration }(P E T) & 6\end{array}$

Section S3: The use of soil moisture content as an indicator of plant water availability $\quad 9$

Section S4: Determining the well-watered reference surface conductance (i.e. $G_{\mathrm{S}, \mathrm{ref}, \mathrm{ww}}$ ) 10

Section S5: The relationship between VPD and soil moisture content at various timescales

Section S6: The site-specific parameterizations for $G_{\mathrm{S}, \text { ref }}$ and $m \quad 15$

Section S7: Effects of other meteorological drivers on $G_{\mathrm{S}, \mathrm{ref}} \quad 17$

Section S8: Future projections - model estimates and downscaling 20 
Section S1: Ameriflux Data Quality Control and filtering: Ameriflux Study Sites are described in Table S1:

Table S1: The Ameriflux synthesis sites. ' $h$ ' indicates canopy height. The 'DOY start' and 'DOY end" dates indicate the start and end of the sitespecific analysis period, which is assumed to be the period of time during which leaf area index is relatively contstant. DI_PM indicates the dryness index (= mean annual potential evapotranspiration/precipitation) determined using the Penman-Monteith model for potential evapotranspiration. 'MAP' is mean annual precipitation derived from the FLUXNET database. Sites that are included in the analysis of future climate effects are indicated with a

\begin{tabular}{|c|c|c|c|c|c|c|c|c|c|c|c|c|c|}
\hline SITE NAME & CODE & LAT & LONG & STATE & TYPE & $\begin{array}{c}\boldsymbol{h} \\
(\mathrm{m})\end{array}$ & Years used & $\begin{array}{l}\text { DOY } \\
\text { Start }\end{array}$ & $\begin{array}{l}\text { DOY } \\
\text { End }\end{array}$ & DI_PM & $\begin{array}{l}\text { MAP } \\
(\mathrm{mm})\end{array}$ & $\begin{array}{c}\text { Future } \\
\text { analysis? }\end{array}$ & Reference \\
\hline ARM - MAIN & US-ARM & 36.61 & -97.49 & OK & CRO & 0.5 & 2003-2012 & 141 & 239 & 1.52 & 843 & $\mathrm{Y}$ & 1 \\
\hline Bartlett Experimental Forest & US-BAR & 44.06 & -71.29 & NH & DBF & 19 & $2005-2011$ & 169 & 225 & 0.76 & 1246 & & 2 \\
\hline Black Hills & US-BLK & 44.16 & -103.65 & SD & ENF & 12 & 2004-2008 & 169 & 225 & 2.4 & 574 & & \\
\hline Blogett & US-BLO & 38.9 & -120.63 & $\mathrm{CA}$ & ENF & 7 & 2001-2007 & 170 & 250 & 1.08 & 1226 & & 3 \\
\hline Bondville Main & US-BO1 & 40.01 & -88.29 & $\mathrm{IL}$ & $\mathrm{CRO}$ & 3 & 2001-2008 & 210 & 270 & 1.02 & 991 & $\mathrm{Y}$ & 4 \\
\hline Brooks Field 11 & US-BR3 & 41.97 & -93.69 & IA & CRo & 1 & 2005-2011 (odd) & 200 & 250 & 0.67 & 847 & & 5 \\
\hline Duke Forest hardwoods & US-DK2 & 35.97 & -79.09 & $\mathrm{NC}$ & DBF & 27 & 2001-2008 & 141 & 239 & 1.24 & 1170 & $\mathrm{Y}$ & 6,7 \\
\hline Duke Forest loblolly pine & US-DK3 & 35.98 & -79.09 & $\mathrm{NC}$ & ENF & 16.5 & 2001-2008 & 127 & 253 & 1.37 & 1170 & $\mathrm{Y}$ & 6,7 \\
\hline Duke Forest open field & US-DK1 & 35.97 & -79.1 & $\mathrm{NC}$ & GRA & 1 & $2001-2008$ & 141 & 239 & 1.18 & 1170 & $\mathrm{Y}$ & 6,7 \\
\hline Fermi Agriculture & US-IB1 & 41.86 & -88.22 & $\mathrm{IL}$ & CRO & 0.3 & 2005-2011 (odd) & 200 & 250 & 0.56 & 929 & & 8 \\
\hline Fermi Prairie & US-IB2 & 41.84 & -88.24 & IL & GRA & 0.3 & $2005-2011$ & 155 & 225 & 0.918 & 930 & & 8 \\
\hline Flagstaff Managed Forest & US-FMF & 35.09 & -111.763 & $\mathrm{AZ}$ & ENF & 18 & $2006-2010$ & 169 & 239 & 4.02 & 546 & & 9 \\
\hline Flagstaff Unmanaged Forest & US-FUF & 35.09 & -111.76 & $\mathrm{AZ}$ & ENF & 18 & $2006-2010$ & 169 & 267 & 3.38 & 562 & & 9 \\
\hline Freeman Ranch & US-FR2 & 29.95 & -98 & TX & SAV & 4 & $2005-2008$ & 113 & 281 & 2.15 & 864 & & 10 \\
\hline GLEES & US-GLE & 41.36 & -106.24 & WY & ENF & 12.1 & $2005-2012$ & 210 & 240 & 0.93 & 525 & & 11 \\
\hline Kansas Field Station & US-KFS & 39.06 & -95.19 & KS & GRA & 0.5 & $2008-2012$ & 140 & 253 & 1.02 & 1014 & & 12 \\
\hline Kendall Grassland & US-WKG & 31.74 & -109.94 & $\mathrm{AZ}$ & GRA & 0.1 & $2005-2012$ & 113 & 281 & 4.36 & 407 & & 13 \\
\hline KennedyScrub Oak & US-KS2 & 28.61 & -80.67 & FL & SRB & 1.5 & $2000-2006$ & 29 & 337 & 0.8 & 1310 & & \\
\hline Konza Prairie & US-KON & 39.08 & -96.56 & KS & GRA & 0.4 & $2007-2012$ & 141 & 239 & 1.4 & 867 & & 12 \\
\hline Lucky Hills Shrubland & US-WHS & 31.75 & -110.05 & $\mathrm{AZ}$ & SRB & 1 & 2008-2012 & 113 & 281 & 7.89 & 320 & $\mathrm{Y}$ & 13 \\
\hline Mary's River Fir & US-MRF & 44.65 & -123.55 & OR & ENF & 34 & $2006-2011$ & 141 & 253 & 0.45 & 1820 & & 14 \\
\hline Mead Irrigated & US-NE1 & 41.17 & -96.48 & $\mathrm{NE}$ & CRO & 1 & 2001-2012 & 200 & 250 & 0.862 & 790 & & 15 \\
\hline Mead Rainfed & US-NE3 & 41.18 & -96.44 & $\mathrm{NE}$ & CRO & 1 & 2001-2011 (odd) & 200 & 250 & 0.429 & 784 & & 15 \\
\hline Metolius Intermediate Pine & US-ME2 & 44.45 & -121.56 & OR & ENF & 22 & 2002-2012 & 169 & 225 & 2.55 & 523 & $\mathrm{Y}$ & 16 \\
\hline Metolius Second Young Pine & US-ME3 & 44.5 & -121.62 & OR & ENF & 3 & $2004-2007$ & 155 & 220 & 1.41 & 719 & & 17 \\
\hline Missouri Ozark Site & US-MOZ & 38.74 & -92.2 & MO & DBH & 24.2 & 2004-2010 & 141 & 239 & 1.89 & 986 & $\mathrm{Y}$ & 18,19 \\
\hline
\end{tabular}


Table S1 continued

\begin{tabular}{|c|c|c|c|c|c|c|c|c|c|c|c|c|c|}
\hline SITE NAME & CODE & LAT & LONG & STATE & TYPE & $\begin{array}{c}\boldsymbol{h} \\
(\mathrm{m})\end{array}$ & Years used & $\begin{array}{l}\text { PGS } \\
\text { Start }\end{array}$ & $\begin{array}{l}\text { PGS } \\
\text { End }\end{array}$ & DI_PM & $\begin{array}{l}\text { MAP } \\
(\mathrm{mm})\end{array}$ & $\begin{array}{c}\text { Future } \\
\text { analysis? }\end{array}$ & Reference \\
\hline Morgan-Monroe State Forest & US-MMS & 39.32 & -86.41 & $\mathrm{IN}$ & DBF & 27 & $2000-2012$ & 141 & 239 & 1.43 & 1032 & $\mathrm{Y}$ & 20 \\
\hline NC loblolly pine & US-NC2 & 35.8 & -76.67 & $\mathrm{NC}$ & ENF & 14.1 & $2005-2010$ & 113 & 267 & 1.24 & 1320 & & 21 \\
\hline Niwot Ridge & US-NR1 & 40.03 & -105.55 & $\mathrm{CO}$ & ENF & 11.5 & $2000-2012$ & 160 & 230 & 1.76 & 800 & $\mathrm{Y}$ & 22 \\
\hline Oak Openings & US-OHO & 41.55 & -83.84 & $\mathrm{OH}$ & DBF & 24 & 2004-2012 & 160 & 239 & 1.2 & 849 & $\mathrm{Y}$ & 23 \\
\hline Santa Rita Creosote & US-SRC & 31.91 & -110.84 & $\mathrm{AZ}$ & SRB & 1.7 & $2008-2012$ & 57 & 281 & 5.56 & $294^{*}$ & & 24 \\
\hline Santa Rita Grassland & US-SRG & 31.79 & -110.83 & $\mathrm{AZ}$ & GRA & 0.5 & 2008-2014 & 85 & 267 & 5.85 & 420 & & \\
\hline Santa Rita Mesquite & US-SRM & 31.82 & -110.87 & $\mathrm{AZ}$ & SAV & 2.5 & 2004-2012 & 71 & 281 & 8.06 & 380 & $\mathrm{Y}$ & 13 \\
\hline Sylvania & US-SYV & 46.24 & -89.35 & MI & ENF & 22 & $2001-2008$ & 169 & 239 & 0.8 & 380 & $\mathrm{Y}$ & 25 \\
\hline Tonzi Ranch & US-TON & 38.43 & -120.97 & $\mathrm{CA}$ & SAV & 9 & $2001-2012$ & 100 & 170 & 3.48 & 559 & $\mathrm{Y}$ & 26 \\
\hline U. of MI Biological Station & US-UMB & 45.56 & -84.71 & MI & DBF & 21 & $2007-2012$ & 169 & 239 & 1.347 & 803 & & 27 \\
\hline Vaira Ranch & US-VAR & 38.41 & -120.95 & $\mathrm{CA}$ & GRA & 0.55 & $2000-2012$ & 100 & 170 & 2.28 & 559 & $\mathrm{Y}$ & 26 \\
\hline Walker Branch & US-WBW & 35.96 & -84.29 & $\mathrm{TN}$ & DBH & 25 & $1998-2006$ & 141 & 253 & 0.8 & 1372 & $\mathrm{Y}$ & 28 \\
\hline Willow Creek & UW-WCR & 45.81 & -90.08 & WI & DBF & 24.2 & $2000-2012$ & 183 & 225 & 0.59 & 787 & & 25 \\
\hline
\end{tabular}

Mean annual precipitation data were not reported to FLUXDATA.org for this site; MAP is therefore that reported in reference 24 
Half-hourly or hourly records of eddy-covariance derived ET and ancillary meteorological data were obtained from 38 Ameriflux sites in the continental U.S. Sites were chosen for inclusion in the study if at least four years of data, including soil moisture data, were available and generally free of large gaps of missing data, though most flux records were much longer (see Table S1).

Hourly data quality control: The ET data were subjected to a standardized quality control procedure whereby data were first filtered to remove missing data and ET measurements greater than $2 \mathrm{~mm} /$ hour or less than $0.6 \mathrm{~mm} /$ hour. Meteorological data were also screened for obvious outliers (i.e. air temperature less than $-30^{\circ} \mathrm{C}$ or greater than $50^{\circ} \mathrm{C}, V P D<0$, net radiation less than $-500 \mathrm{~W} \mathrm{~m}^{-2}$ or greater than $1500 \mathrm{~W}$ $\mathrm{m}^{-2}$ ). Data were not gapfilled; rather, all analysis relied only on screened observations. Most of the analysis was limited to daytime periods $\left(\mathrm{Rn}>50 \mathrm{~W} \mathrm{~m}^{-2}\right)$ when wind speed exceeded $1 \mathrm{~m} \mathrm{~s}^{-1}$ and $V P D>$ $0.6 \mathrm{kPa}$ (to minimize stability effects).

Filtering data to periods of relatively stationary leaf area index: Our analysis includes sites that span a wide range of leaf area index and canopy height, which are variables known to affect vegetative hydraulic functioning ${ }^{29,30}$. Within a site, temporal variation in leaf area or other aspects of canopy architecture were not explicitly considered, though they may also have affected the temporal dynamics of ET. To minimize the influence of those effects, we filtered our data to exclude periods when leaf area was expected to be low or highly dynamic. In evergreen forests, the analysis period was defined to start two weeks after the average date of the last sub-zero hourly air temperature observation, and was defined to end one week before the average date of the first sub-zero hourly air temperature observation in the fall/winter. In deciduous forests and temperate grasslands, the analysis period was defined to start three weeks after the average date of the last sub-zero hourly air temperature observation, and was defined to end two weeks before the average date of the first sub-zero hourly air temperature observation in the fall/winter. In croplands, semi-arid grassland and shrublands, and Mediterranean ecosystems (i.e. US-TON, US-VAR), the analysis period was defined based on previously published site-specific estimates of leaf area or communication from site data providers. The start and end of the analysis period at each site are given in Table S1.

Limiting the analysis to exclude low VPD: When parameterizing the model of Eq. 1 in the main text, we limited the data to those collected when $V P D>1.0 \mathrm{kPa}$. This approach is consistent with other work ${ }^{31}$, and recognizes that estimates of conductances become unstable when they are derived by dividing measured water fluxes by near-zero VPD. Furthermore, at low $V P D$ when atmospheric conditions are often stable, boundary layer conductances may become an important constraint on observations of ET. These challenges are exacerbated by the fact that, at low VPD, ET fluxes are also low and of a magnitude comparable to the uncertainty in the observations themselves.

When using the soil-moisture-specific parameterizations of Eq. 1 to determine the total growing season limitations to $G_{\mathrm{S}}$ and $E T$, we assume that $V P D$ is not limiting when it is less than $0.6 \mathrm{kPa}$. To an extent, this assumption is one of convenience, since the model of Eq. 1 can produce large errors when $V P D$ is close to zero (and $\ln (V P D)$ is approaching infinity). We note, however, that the difference between $P E T$ and $E T$ is typically near zero or negative when $V P D<0.6 \mathrm{kPa}$ (Figure $\mathrm{S} 1$ ). Specifically, across all sites, a linear model for $P E T-E T$ as a function of $V P D$ tends to cross zero at $V P D=0.6 \mathrm{kPa}$ on average (std.dev $=$ $0.3 \mathrm{kPa}$ ), indicating that at low $V P D, E T$ is not limited from its potential rate. 

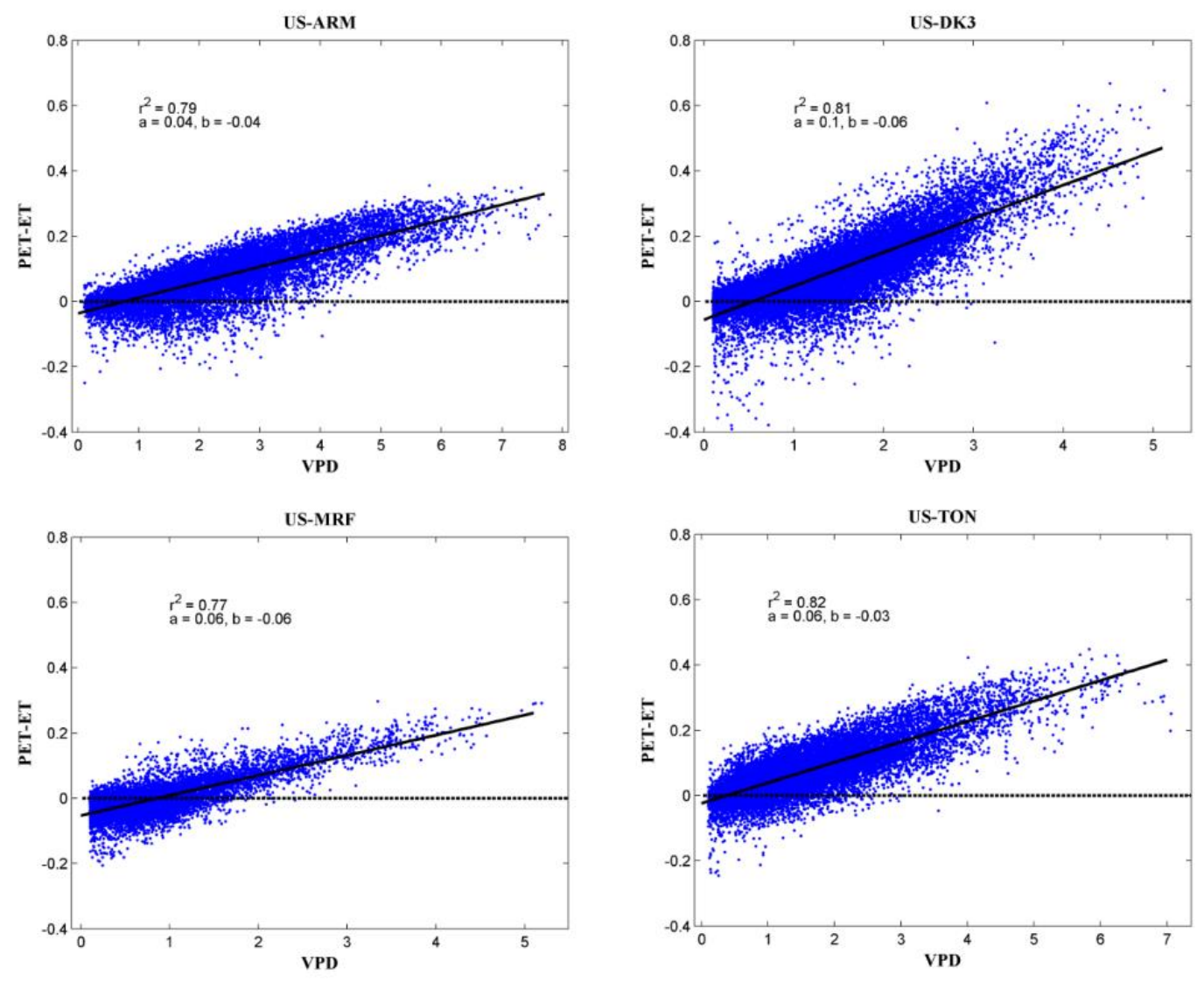

Figure S1: The relationship between PET-ET (i.e. the difference between potential and observed ET) as a function of VPD for four representative sites. The slope $(a)$ and intercept $(b)$ of the derived linear relationship are also shown, together with the coefficient of correlation $\left(r^{2}\right)$

Estimating the dryness index: The estimates of the dryness index (DI = PET/P), which rely on annual estimate of PET and $\mathrm{P}$, are sensitive to missing meteorological data, and in particular missing precipitation data. As evidence, when the mean annual precipitation was determined from the hourly Level 2 Ameriflux data, the ratio of observed ET to observed precipitation (i.e. the evaporative fraction) exceeded 1.0 for about $30 \%$ of sites. A multi-year evaporative fraction greater than 1.0 is physically possible if a site experiences significant run-on soil moisture or groundwater convergence; however, in Ameriflux sites that tend to be biased to flat locations, significant run-on is not likely in most sites. Therefore, we calculated the DI using the long-term mean annual precipitation reported by each site to the Fluxnet Database (http://fluxnet.ornl.gov/) instead of calculating mean annual precipitation from the Level 2 Ameriflux data. There may be some discrepancies between the DI estimated this way and the true DI for each site's study period if the mean annual precipitation during the study period is much different than the longer-term reported average. However, because the site-specific study periods are generally long and are not limited to the same years (see Table S1), systematic biases across sites (for example due to the occurrence of a large regional drought event) should be minimal. 


\section{Section S2: Selecting the model for potential evapotranspiration (PET)}

In this study, the potential evapotranspiration rate (PET) is used to calculate the dryness index, and also to quantify limitations to $E T$ imposed by soil moisture and $V P D$. In many previous studies focused on understanding ecosystem hydrologic processes, the PET has been calculated using the Priestley-Taylor equation $^{32}$, which may be represented as:

$P E T_{P T}=a_{P T} \frac{S \cdot R_{n}}{S+\gamma} \cdot \frac{1}{\lambda_{V}}$

where $a_{P T}=1.26$ is the Priestley-Taylor coefficient, $S$ is the temperature-dependent slope of the saturation-vapor pressure curve, $\gamma$ is the temperature-dependent psychrometric constant, and $\lambda_{V}$ is the temperature-dependent latent heat of vaporization. In this study, which is strongly focused on atmospheric limitations to $E T$, we estimate PET using the Penman-Monteith ${ }^{33,34}$ approach, which in addition to accounting for energy constraints to $E T$, also accounts for aerodynamic and atmospheric constraints. The Penman-Monteith equation for PET may be expressed as:

$P E T_{P M}=\frac{S \cdot R_{n}+c_{p} \rho_{a} g_{a} V P D}{\lambda_{V}\left[S+\gamma\left(1+\frac{g_{a}}{G_{S}}\right)\right]}$

where $S$ is the temperature-dependent slope of the saturation-vapor pressure curve, $R_{\mathrm{n}}$ is net radiation, $p_{\mathrm{a}}$ is the density of dry air, $\gamma$ is the temperature-dependent psychrometric constant, $\lambda_{\mathrm{V}}$ is the temperaturedependent latent heat of vaporization, $g_{\mathrm{a}}$ is the aerodynamic conductance, and $c_{\mathrm{p}}$ is the specific heat capacity for dry air.

The formal definition of the Penman-Monteith equation for canopy evapotranspiration relies on a big-leaf assumption, and in many applications $G_{S}$ is equated to the canopy-level stomatal conductance ${ }^{35}$. However, ecosystem evapotranspiration includes a non-negligible contribution from soil evaporation (typically on the order of $15-30 \%$ for a range of biomes ${ }^{36,37,38,39,40}$ ). In modeling studies, this problem is often met with a two-source (i.e. canopy and soil) modeling procedure where both canopy and soil evaporation are independently simulated from Penman-Monteith type equations. However, in data driven applications like this one, when surface conductance is derived by inverting the Penman-Monteith equation from measured ecosystem scale $E T$ observations, the derived $G_{S}$ is influenced by soil evaporation, and should not be assumed to be representative of canopy stomatal conductance alone ${ }^{35,41,42,43,44}$. Because soil evaporation increases linearly with $V P D$, a greater ratio of soil evaporation to total evapotranspiration will tend to reduce the magnitude of the VPD sensitivity parameter $m$.

The aerodynamic conductance $\left(g_{\mathrm{a}}\right)$ is formulated as a function of wind speed and canopy height after Campbell \& Norman $(1998)^{45}$ as:

$g_{a}=\frac{U \cdot k^{2}}{\left[\ln \left(\frac{z_{m}-z}{z_{o}}\right)\right]^{2}}$

Where $U$ is the measured wind speed $(\mathrm{m} / \mathrm{s}), k$ is the Von Karman Constant, $z_{\mathrm{m}}$ is the measurement height, $z_{\mathrm{d}}$ is the zero plane displacement, and $z_{\mathrm{o}}$ is the momentum roughness length. The $z_{\mathrm{d}}$ and $z_{\mathrm{o}}$ where taken as $0.67 h$ and $0.1 h$, respectively, where $h$ is canopy height, as is common practice in the absence of other information about these parameters ${ }^{45,46}$. In some applications, it is common to incorporate a correction for stability effects on $g_{\text {a }}$ via the modification:

$g_{a}=\frac{U \cdot k^{2}}{\left[\ln \left(\frac{z_{m}-z_{d}}{z_{o}}\right)+\Psi_{H}\right]^{2}}$ 
101 where the diabatic correction factor $\Psi_{H}$ can be specified as a function of the ratio of convective to mechanical production of turbulence as described in Campbell \& Norman (1998) ${ }^{45}$.

Filtering the data to remove observations collected when $V P D<0.6 \mathrm{kPa}$ and wind speed $<1 \mathrm{~m} \mathrm{~s}^{-1}$ should minimize the influence of stability effects on the derived surface conductance. To be sure, we repeated the analysis in a subset of sites spanning the range of dryness index for three scenarios: 1) no stability corrections to $g_{a}$ (i.e. using Eq. S3) and no wind speed filter, 2) no stability corrections to $g_{\text {a }}$ (i.e. using Eq. S3) with the wind speed filter, and 3) stability corrections to $g_{a}$ using Eq. S4 with the wind speed filter. In US-DK3, the relationship between $g_{\mathrm{a}}$ and $V P D$ was similar in all scenarios. In the other sites, the relationship between $g_{\mathrm{a}}$ and $V P D$ was similar for scenario $1 \& 2$, but scenario 3 resulted in higher $g_{\mathrm{a}}$ at high $V P D$.

Importantly, however, regardless of which scenario was used, the relationship between $G_{\mathrm{S}}$ and $V P D$ was similar in all sites, and nearly indistinguishable in most. Thus, we elected not to correct $g_{\mathrm{a}}$ for stability effects in order to minimize additional uncertainties associated with the parameterization of the stability correction itself.
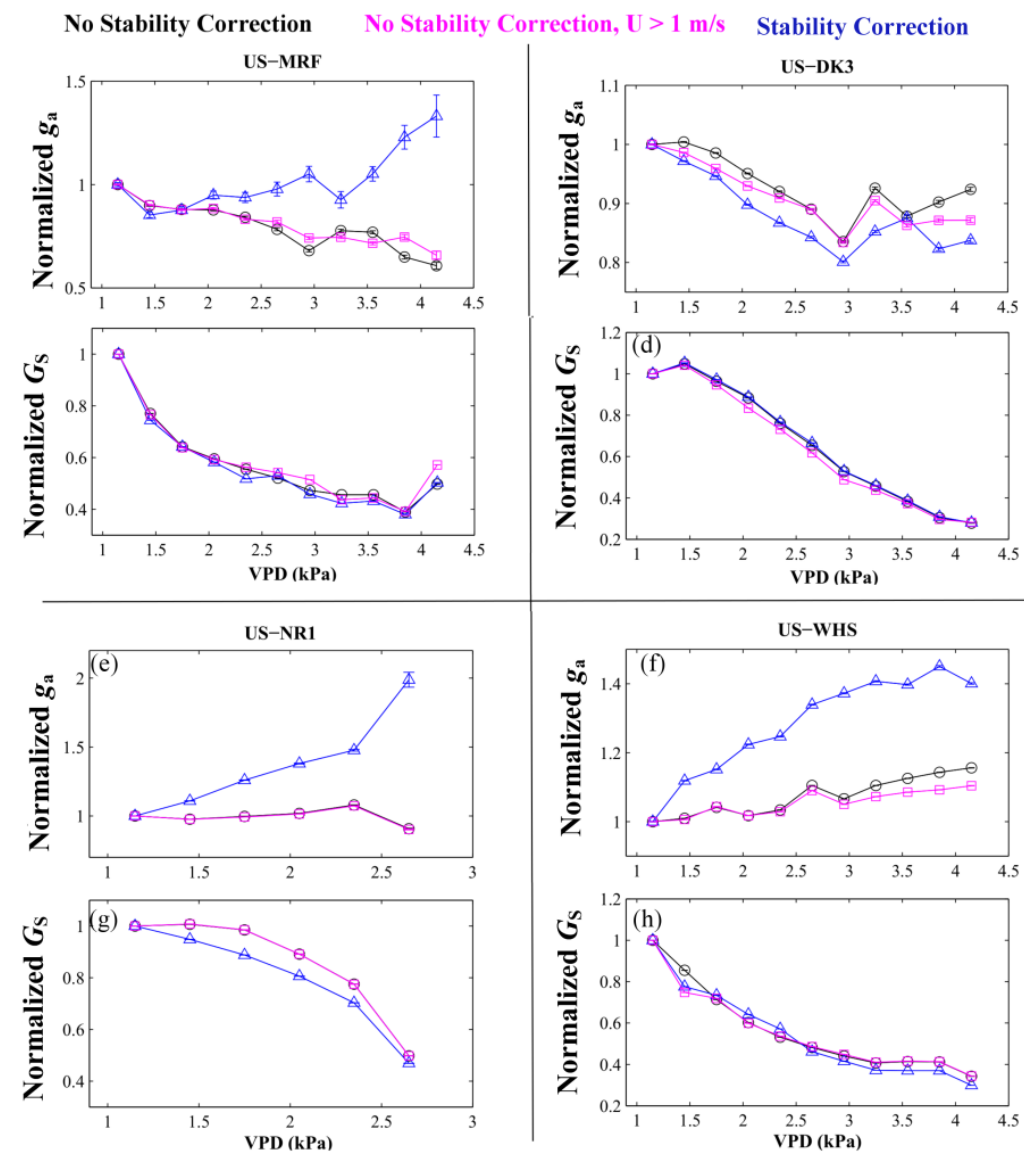

Figure S2: The relationship between aerodynamic conductance and VPD (panels $a, c, e, g$ ), and surface conductance $\left(G_{\mathrm{S}}\right)$ and VPD (panels $b, d, f$, and $h$ ), showing results from the three stability correction scenarios. 
When calculating $P E T_{\mathrm{PM}}$ for use in determining the site dryness index, we elected to set $G_{\mathrm{S}}$ in Eq. S2 equal to $.0148 \mathrm{~m} / \mathrm{s}$. This represents the highest value of the reference, well-watered surface conductance rate (i.e. $G_{\mathrm{S} \text {,ref,ww }}$ ) observed across the study domain. This approach of using a finite $G_{\mathrm{S}}$ to determine $P E T$ is conceptually consistent with the use of the Priestly-Taylor equation, since the parameter $a_{P T}$ is set to approximate well-watered evapotranspiration rates from terrestrial ecosystems, and not, for example, open water (over which $G_{\mathrm{S}}$ is infinite).

The agreement between the dryness index calculated using $P E T_{\mathrm{PT}}$ and $P E T_{\mathrm{PM}}$ is shown for reference in Figure S2. The dryness index values tend to be higher when calculated using the Penman-Monteith equation, but overall the two estimates of PET are strongly correlated.

128

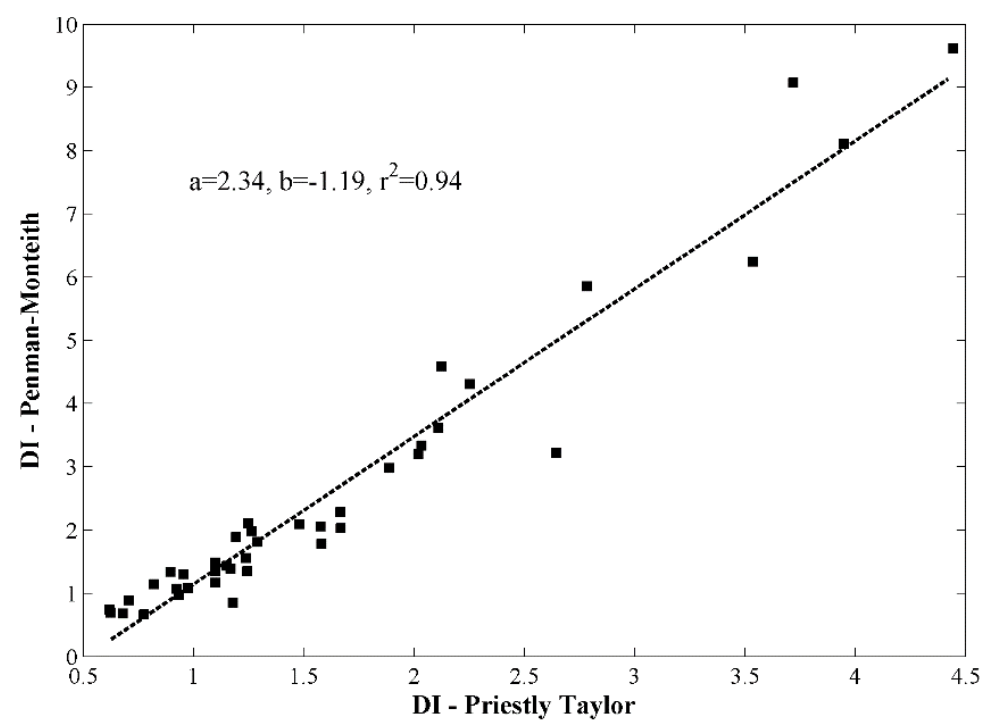

Figure S3: The relationship between dryness index estimated using the Penman-Monteith and Priestly-Taylor Models for PET. 
143

144

145

146

147

148

149

150

151

152

153

154

155

156

157

158

159

160

161

162

163

164

165

166

167

168

169

170

\section{Section S3: The use of soil moisture content as an indicator of plant water availability}

We elected to use the total volumetric soil moisture $(\theta)$ in the top $30 \mathrm{~cm}$ as the primary proxy for plant water availability. Most Ameriflux sites rely on time-domain reflectrometry (TDR) measurements for $\theta$, which often require a site-specific calibration. Details of these site-specific calibrations are not available in the Ameriflux database, and thus cross-site comparisons of soil moisture content should be approached with caution. In other studies, the relative extractable water (REW, which represents soil moisture content scaled by the minimum and maximum observed values) is used instead to facilitate cross-site comparisons of ecosystem water use $\mathrm{u}^{47,48}$.

It could be argued that soil water potential $\left(\Psi_{S}\right)$ is a more appropriate measure of soil water availability than either $\theta$ or REW, since water tension in the soil is an important physical driver of water movement through soil matrices and plants ${ }^{49,50}$. Unfortunately, soil water potential is rarely measured in the field. Occasionally, laboratory-based dry down experiments are used to derive an empirical relationship between $\theta$ and $\Psi_{S}$. This relationship is not linear ${ }^{49}$, though it is monotonically increasing. As illustrated in Figure $S 4$, in sites for which estimates of $\Psi_{S}$ are available, $\Psi_{S}$ increases more rapidly with increasing $\theta$ when the latter is low; as a result, the results of this study associated with the drier soil moisture bins will likely reflect the response to a relatively wider range of $\Psi_{S}$ conditions.

It is important to note that the choice of the soil moisture variable (i.e. $\theta$ vs. REW vs. $\Psi_{S}$ ) has no effect on our primary results concerning the relative importance of soil moisture versus VPD limitations to surface conductance and ET (e.g. the results presented in Figures $3 \& 4$ in the main text). This is because the analytical approach relies on binning the data into quantiles defined by the $0-15^{\text {th }}, 15^{\text {th }}-30^{\text {th }}, 30^{\text {th }}-50^{\text {th }}, 50^{\text {th }}$ $70^{\text {th }}, 70^{\text {th }}-90^{\text {th }}$, and $90^{\text {th }}-100^{\text {th }}$ percentiles of $\theta$, and then parameterizing Eq. 1 within each bin. Because the relationships between $\theta$ and REW and $\Psi_{S}$ are all monotonically increasing, the same data will fall into the same bins regardless of which soil moisture metric is used.

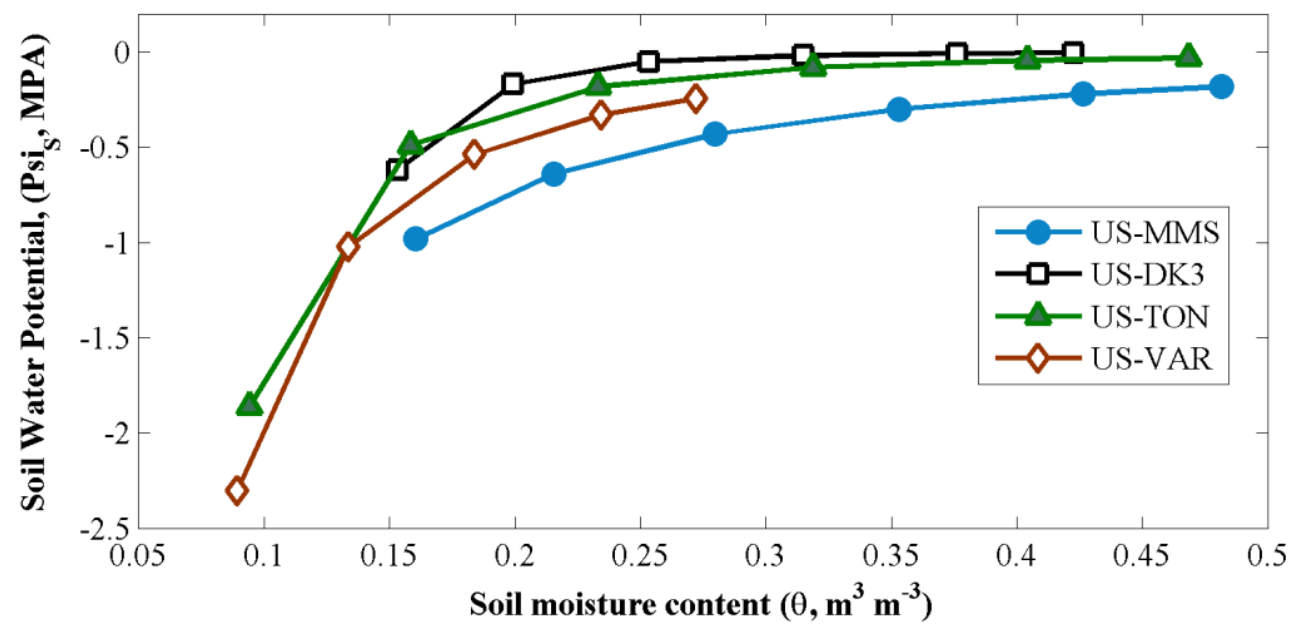

Figure S4: The relationship between soil water potential and soil moisture content in four study sites for which sitespecific relationships between $\theta$ and $\Psi_{S}$ were available (see references Wayson et al. 2016 for US-MMS, Hacke et al. 2000 for US-DK3, and Baldocchi et al. 2004 for US-TON and US-VAR. 
S4. Determining the well-watered reference surface conductance (i.e. $\left.G_{\mathrm{S}, \mathrm{ref}, \mathrm{ww}}\right)$.

174 The limitations to $G_{S}$ imposed by soil moisture and $V P D$ were estimated by comparing hourly estimates of $175 G_{\mathrm{S}}$ to the well-watered reference value of surface conductance (i.e. $G_{\mathrm{S}}$,ref,ww $)$. This parameter represents the surface conductance when soil moisture content exceeds the $90^{\text {th }}$ percentile in each site, and $0.9<$ $V P D<1.1 \mathrm{kPa}$. Choosing the reference $V P D$ of $1.0 \mathrm{kPa}$ is consistent with previous work ${ }^{31}$. The approach recognizes the fact that surface conductance estimates at low $V P D$ are sensitive to biases introduced by low boundary layer conductance and instabilities in the determination of $G_{\mathrm{S}}$ from $E T$ when $V P D$ is low.

180

181

182

183

184

185

186

187

188

2

The magnitude of $G_{\mathrm{S}, \mathrm{ref}, \mathrm{ww}}$ tends to be low in sites with a high dryness index, and variable but generally higher in more mesic sites (Figure S5). The low $G_{\mathrm{S} \text { ref,ww }}$ in the driest sites is expected, as canopy stomatal conductance - an important component of $G_{S}$ - is driven by leaf area ${ }^{51}$, which is very low in semi-arid ecosystems. The variability in $G_{\mathrm{S}, \text { ref,ww }}$ in more mesic sites may be explained, to an extent, by variation in leaf area as well as variation in canopy height, which introduces another important structural control on canopy stomatal conductance ${ }^{30,52}$. While these sources of variability in well-watered $G_{\mathrm{S}}$ are an important long-term constraint on ecosystem carbon and water cycling, they are not the focus of this present study. We point readers elsewhere ${ }^{32}$ for a more thorough treatment of the topic.

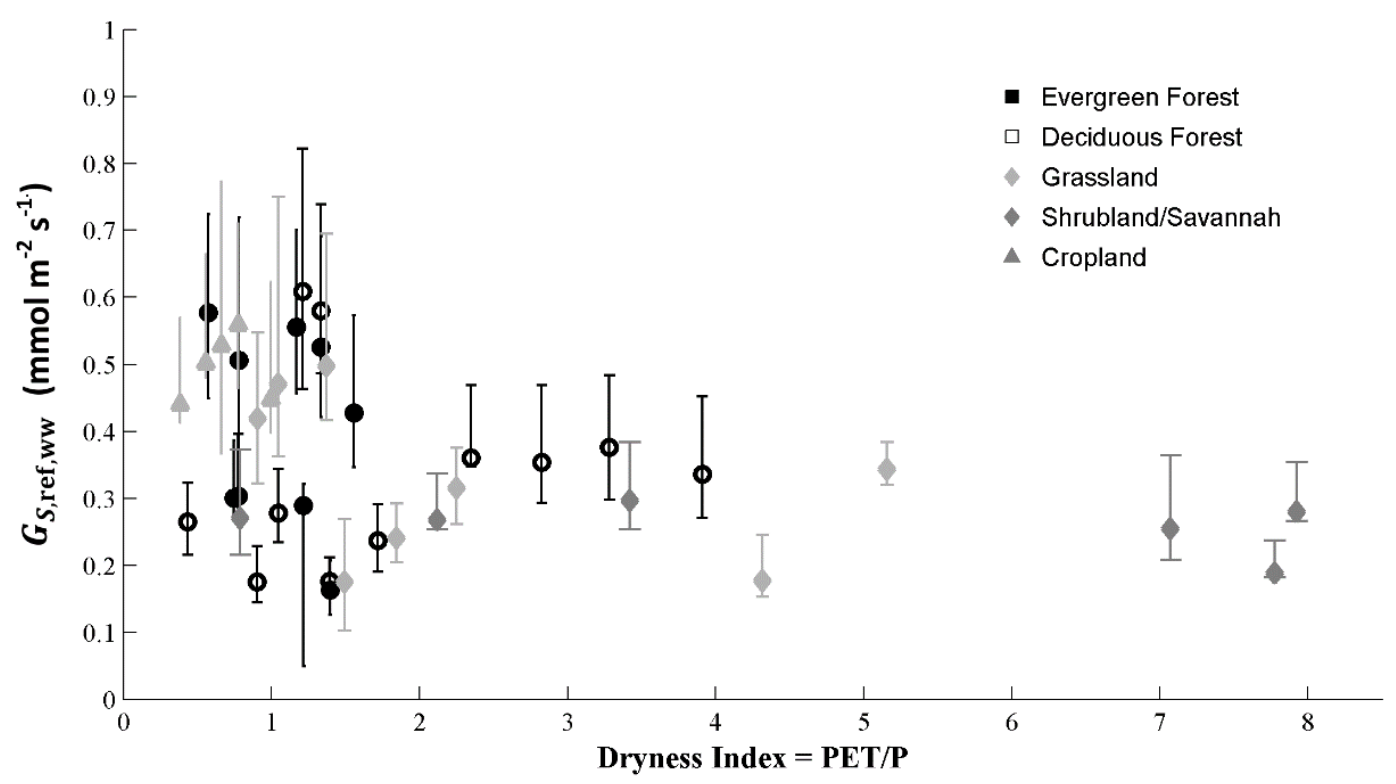

Figure S5: The relationship between the well-watered reference surface conductance and dryness index. Error bars indicates the $50 \%$ confidence interval on the estimate of $g_{c, r e f, w w}$ as derived from a non-parametric bootstrap. 


\section{Section S5: The relationship between VPD and $\theta$ at various timescales}

Our analysis leverages the fact that while $V P D$ and $\theta$ are moderately to strongly correlated at long timescales (i.e. monthly to annual), they are relatively weakly coupled at the hourly and daily timescales over which Ameriflux data is gathered. In Figure 1 of the main text, we present a summary of the correlation between $\theta$ and VPD averaged across all study sites for varying averaging periods (i.e. seasonal, monthly, weekly, daily, and hourly). For illustrative purpose, we show the data that inform that summary presentation for one representative site in Figure S6, and present the statistics of the linear regressions between the two variables over the various timescales in Table $\mathrm{S} 2$.
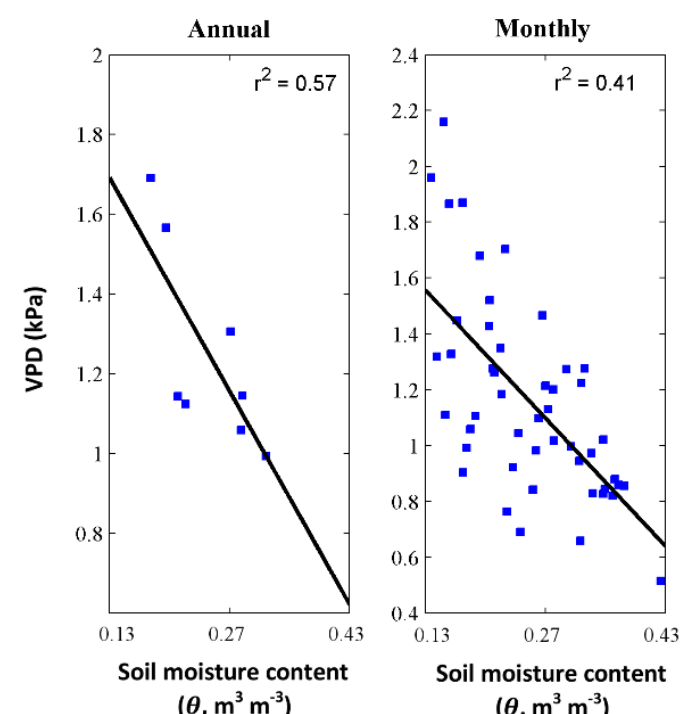

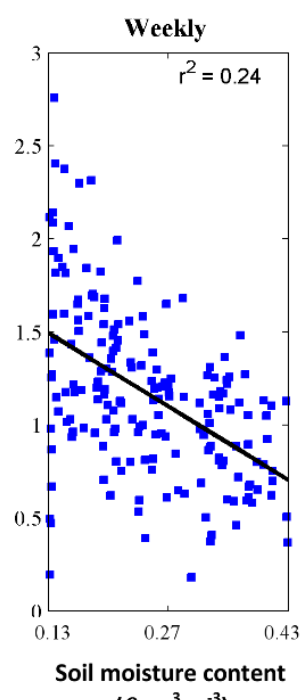

$\left(\theta, \mathrm{m}^{3} \mathrm{~m}^{-3}\right)$

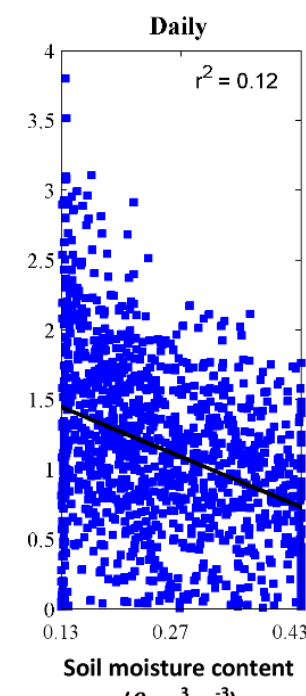

$\left(\theta, \mathrm{m}^{3} \mathrm{~m}^{-3}\right)$

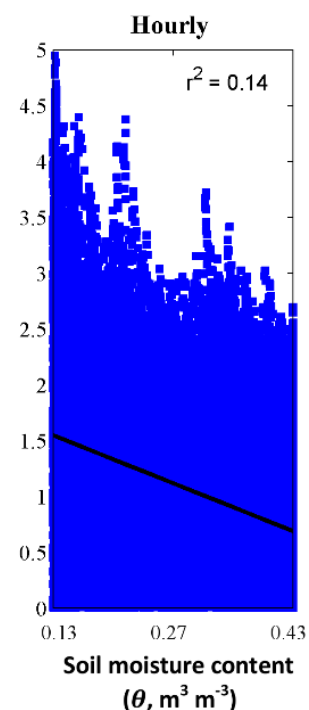

$\left(\theta, \mathrm{m}^{3} \mathrm{~m}^{-3}\right)$

Figure S6: The relationship between vapor pressure deficit (VPD) and soil moisture content $(\theta)$ when both are averaged over various timescales. Data are from the US-DK3 (Duke Pine Forest). 
Table S2: The slope, intercept, and correlation coefficient of the relationship between vapor pressure deficit (VPD) as a linear function of soil moisture content $(\theta)$ inferred by averaging the data over various timescales. In general, the slope and intercept parameters are relatively stationary across timescales, but the two variables become increasingly decoupled (i.e. $r^{2}$ is lower) at shorter timescales.

\begin{tabular}{|c|c|c|c|c|c|c|c|c|c|c|c|c|c|c|c|}
\hline & \multicolumn{5}{|c|}{ Slope } & \multicolumn{5}{|c|}{ Intercept } & \multicolumn{5}{|c|}{ correlation coefficient $\left(\mathbf{r}^{2}\right)$} \\
\hline & y ear & month & week & day & hour & year & month & week & day & hour & year & month & week & day & hour \\
\hline ARM & -0.91 & -1.10 & -1.28 & -1.36 & -0.98 & 2.54 & 2.54 & 2.70 & 2.76 & 1.96 & 0.38 & 0.12 & 0.15 & 0.14 & 0.06 \\
\hline BAR & -0.46 & -0.13 & -0.24 & -0.24 & -0.37 & 1.15 & 0.97 & 1.00 & 0.98 & 0.94 & 0.55 & 0.02 & 0.04 & 0.02 & 0.03 \\
\hline BLK & -0.65 & -0.32 & -0.47 & -0.60 & -0.19 & 1.73 & 1.50 & 1.63 & 1.67 & 1.06 & 0.40 & 0.04 & 0.07 & 0.04 & 0.01 \\
\hline BLO & 0.18 & -0.81 & -0.39 & -0.21 & -1.16 & 1.80 & 1.95 & 1.90 & 1.89 & 2.08 & 0.08 & 0.20 & 0.04 & 0.01 & 0.32 \\
\hline BO1 & -0.41 & -0.44 & -0.63 & -0.48 & -0.29 & 1.30 & 1.36 & 1.45 & 1.28 & 1.01 & 0.26 & 0.22 & 0.24 & 0.10 & 0.01 \\
\hline BR3 & 0.73 & 0.27 & -0.31 & -0.50 & 0.13 & 0.62 & 0.94 & 1.22 & 1.28 & 0.88 & 0.65 & 0.10 & 0.09 & 0.15 & 0.00 \\
\hline DK1 & -1.40 & -0.96 & -1.04 & -0.96 & -0.82 & 1.83 & 1.60 & 1.66 & 1.60 & 1.53 & 0.67 & 0.40 & 0.31 & 0.19 & 0.13 \\
\hline DK2 & -1.79 & -0.94 & -1.08 & -1.01 & -0.78 & 1.97 & 1.57 & 1.65 & 1.61 & 1.53 & 0.81 & 0.36 & 0.31 & 0.21 & 0.13 \\
\hline DK3 & -1.07 & -0.92 & -0.79 & -0.72 & -0.86 & 1.69 & 1.56 & 1.49 & 1.45 & 1.55 & 0.57 & 0.42 & 0.25 & 0.12 & 0.15 \\
\hline FMF & 0.10 & -0.56 & -0.65 & -1.09 & -0.88 & 1.55 & 1.82 & 1.94 & 2.25 & 1.79 & 0.01 & 0.07 & 0.09 & 0.12 & 0.08 \\
\hline FR2 & -1.70 & -0.92 & -1.50 & -1.30 & -1.13 & 2.42 & 1.98 & 2.34 & 2.21 & 2.00 & 0.98 & 0.18 & 0.55 & 0.33 & 0.14 \\
\hline FUF & -1.25 & -1.20 & -1.32 & -1.43 & -0.91 & 2.18 & 2.09 & 2.20 & 2.25 & 1.66 & 0.95 & 0.64 & 0.57 & 0.40 & 0.16 \\
\hline GLE & 0.06 & 0.03 & 0.13 & 0.14 & 0.61 & 0.96 & 0.93 & 0.91 & 0.90 & 0.20 & 0.03 & 0.01 & 0.04 & 0.01 & 0.16 \\
\hline IB1 & -0.64 & -0.56 & -0.65 & -0.79 & -1.10 & 1.52 & 1.45 & 1.51 & 1.57 & 1.62 & 0.56 & 0.30 & 0.42 & 0.29 & 0.16 \\
\hline IB2 & -0.45 & -0.53 & -0.44 & -0.61 & -0.84 & 1.40 & 1.39 & 1.36 & 1.46 & 1.39 & 0.24 & 0.23 & 0.12 & 0.10 & 0.10 \\
\hline KFS & -2.75 & -1.60 & -1.66 & -1.52 & -1.67 & 2.74 & 2.02 & 2.16 & 2.16 & 2.17 & 0.99 & 0.34 & 0.36 & 0.25 & 0.28 \\
\hline KON & -0.68 & -1.42 & -1.41 & -1.21 & -1.23 & 2.05 & 2.41 & 2.49 & 2.34 & 2.10 & 0.49 & 0.32 & 0.28 & 0.18 & 0.14 \\
\hline KSO & 0.25 & 0.10 & -0.09 & -0.20 & -0.22 & 1.10 & 1.11 & 1.20 & 1.22 & 1.25 & 0.03 & 0.00 & 0.00 & 0.01 & 0.01 \\
\hline ME2 & -0.48 & -0.68 & -0.38 & -0.61 & -1.27 & 1.63 & 1.53 & 1.51 & 1.64 & 1.78 & 0.11 & 0.07 & 0.02 & 0.04 & 0.32 \\
\hline ME3 & 0.62 & -0.48 & -0.37 & -0.63 & -1.38 & 1.79 & 2.00 & 2.03 & 2.17 & 2.11 & 0.06 & 0.08 & 0.02 & 0.04 & 0.28 \\
\hline MMS & -0.96 & -0.42 & -0.29 & -0.33 & -0.78 & 1.52 & 1.18 & 1.09 & 1.12 & 1.32 & 0.43 & 0.13 & 0.05 & 0.04 & 0.11 \\
\hline MOZ & -0.67 & -0.82 & -0.93 & -1.02 & -1.09 & 1.71 & 1.75 & 1.84 & 1.89 & 1.69 & 0.28 & 0.26 & 0.27 & 0.19 & 0.15 \\
\hline MRF & 0.66 & -0.76 & -0.66 & -0.59 & -0.72 & 0.50 & 0.94 & 0.93 & 0.89 & 0.99 & 0.09 & 0.52 & 0.27 & 0.10 & 0.17 \\
\hline $\mathrm{NC} 2$ & -0.24 & -0.27 & -0.21 & -0.27 & -0.45 & 1.34 & 1.30 & 1.28 & 1.30 & 1.29 & 0.48 & 0.12 & 0.04 & 0.03 & 0.04 \\
\hline NE1 & -0.96 & -0.98 & -0.80 & -1.03 & -0.20 & 1.77 & 1.77 & 1.66 & 1.80 & 1.15 & 0.30 & 0.33 & 0.21 & 0.18 & 0.00 \\
\hline NE3 & -1.52 & -0.84 & -0.58 & -0.73 & -0.57 & 1.97 & 1.69 & 1.58 & 1.65 & 1.42 & 0.56 & 0.32 & 0.18 & 0.15 & 0.04 \\
\hline NR1 & -0.31 & -0.25 & -0.38 & -0.38 & -0.05 & 1.07 & 1.03 & 1.07 & 1.08 & 0.66 & 0.27 & 0.17 & 0.16 & 0.06 & 0.00 \\
\hline $\mathrm{OHO}$ & -1.58 & -0.86 & -0.63 & -0.57 & -0.86 & 1.79 & 1.42 & 1.34 & 1.31 & 1.33 & 0.47 & 0.35 & 0.19 & 0.11 & 0.15 \\
\hline SRC & 0.82 & -1.09 & -1.08 & -1.11 & -1.18 & 2.25 & 2.98 & 3.03 & 3.02 & 2.92 & 0.27 & 0.10 & 0.10 & 0.09 & 0.07 \\
\hline SRG & -1.17 & -1.90 & -1.73 & -1.73 & -1.95 & 2.90 & 3.13 & 3.07 & 3.09 & 3.14 & 0.64 & 0.45 & 0.34 & 0.24 & 0.33 \\
\hline SRM & -1.61 & -0.80 & -1.22 & -1.38 & -1.72 & 3.04 & 2.74 & 2.93 & 2.99 & 2.85 & 0.17 & 0.07 & 0.20 & 0.20 & 0.22 \\
\hline SYV & 0.04 & -0.16 & -0.13 & -0.08 & -0.51 & 1.00 & 1.03 & 1.06 & 1.04 & 1.11 & 0.00 & 0.02 & 0.01 & 0.00 & 0.04 \\
\hline TON & -0.33 & -0.27 & -0.45 & -0.51 & -0.64 & 0.88 & 0.83 & 0.90 & 0.91 & 1.06 & 0.47 & 0.05 & 0.12 & 0.11 & 0.08 \\
\hline UMB & 0.09 & -0.95 & -0.69 & -0.68 & -0.80 & 0.88 & 1.25 & 1.15 & 1.13 & 1.20 & 0.03 & 0.54 & 0.30 & 0.18 & 0.17 \\
\hline VAR & -0.32 & -0.57 & -0.51 & -0.56 & -0.56 & 0.87 & 0.98 & 0.93 & 0.95 & 0.98 & 0.17 & 0.27 & 0.18 & 0.13 & 0.09 \\
\hline WBW & -0.83 & -0.22 & -0.30 & -0.41 & -0.59 & 1.52 & 1.12 & 1.18 & 1.23 & 1.32 & 0.13 & 0.03 & 0.05 & 0.06 & 0.07 \\
\hline WCR & 0.12 & 0.04 & -0.06 & -0.16 & 0.02 & 0.47 & 0.49 & 0.56 & 0.60 & 0.41 & 0.05 & 0.00 & 0.00 & 0.01 & 0.00 \\
\hline WHS & -2.49 & -0.69 & -1.38 & -1.49 & -0.95 & 3.65 & 2.76 & 3.17 & 3.24 & 2.61 & 0.51 & 0.03 & 0.16 & 0.17 & 0.05 \\
\hline WKG & -0.03 & -1.05 & -1.09 & -1.16 & -0.99 & 2.38 & 2.63 & 2.77 & 2.82 & 2.41 & 0.00 & 0.12 & 0.15 & 0.13 & 0.06 \\
\hline Mean & -0.62 & -0.67 & -0.71 & -0.76 & -0.77 & 1.68 & 1.63 & 1.69 & 1.71 & 1.55 & 0.36 & 0.20 & 0.18 & 0.13 & 0.12 \\
\hline $\begin{array}{l}\text { Std } \\
\end{array}$ & 0.84 & 0.47 & 0.48 & 0.46 & 0.52 & 0.71 & 0.65 & 0.69 & 0.70 & 0.66 & 0.29 & 0.17 & 0.14 & 0.09 & 0.09 \\
\hline
\end{tabular}


Section S6: Determining soil moisture as compared to VPD constraints to $\boldsymbol{G}_{\mathrm{S}}$ and $\boldsymbol{E T}$ : The growing season $E T$ and meteorological data were sorted into bins representing the $0-15^{\text {th }}, 15^{\text {th }}-30^{\text {th }}, 30^{\text {th }}$ $50^{\text {th }}, 50^{\text {th }}-70^{\text {th }}, 70^{\text {th }}-90^{\text {th }}$, and $90^{\text {th }}-100^{\text {th }}$ percentiles of $\theta$, spanning a gradient of dry to wet conditions in each site. Within each soil moisture bin, we further sorted the data on the basis of VPD; the VPD bins had a width of $0.2 \mathrm{kPa}$, and there were $j=1,2 \ldots N_{\mathrm{i}} V P D$ bins in each soil moisture bin, where $N_{\mathrm{i}}$ varies as a function of the maximum $V P D$ observed at each site. The mean $G_{\mathrm{S}}$ in each bin was determined provided there were more than 10 data points in any given $(i, j)$ bin.

The binned averages were used to derive site- and soil-moisture-specific parameterizations for Eq. 1, which were leveraged to quantify the total growing season average supply and demand limitations to $G_{\mathrm{S}}$ and ET. Briefly, $\theta$ constraints were inferred from changes in the intercept parameter $\left(G_{\mathrm{S}, \mathrm{ref}}\right)$, and $V P D$ constraints were inferred from the sensitivity parameter $m$. Estimates of hourly $G_{\mathrm{S}}$ reflecting either $\theta$ or $V P D$ control for all daytime periods were then subtracted from the $G_{\mathrm{S} \text {,ref,ww }}$ to quantify the magnitude of limitations to $G_{\mathrm{S}}$ attributable to each driver. These estimates of hourly $G_{\mathrm{S}}$ were then used in Eq. 2 to

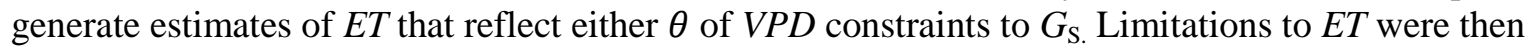
defined as the difference between hourly PET and ET, where the PET is generated using Eq. 2 forced with the site-specific $G_{\mathrm{S}, \text { ref,ww. }}$ In most sites, the reported $\theta$ corresponds to integrated observations over the top $30 \mathrm{~cm}$ of the soil. The soil moisture dynamics in the top $30 \mathrm{~cm}$ may not always be well coupled to soil moisture at depth, which represents a potential source of bias in sites with deeper roots.

In Figure 2 of the main text, we show representative results from four sites. Here are analogous figures for all study sites. The fitted lines, which show the model of Eq. 1 within each soil moisture bin, do not extend below $V P D<1.0 \mathrm{kPa}$, as those data were not used to drive the regressions due again to instabilities in the observations at low VPD. 

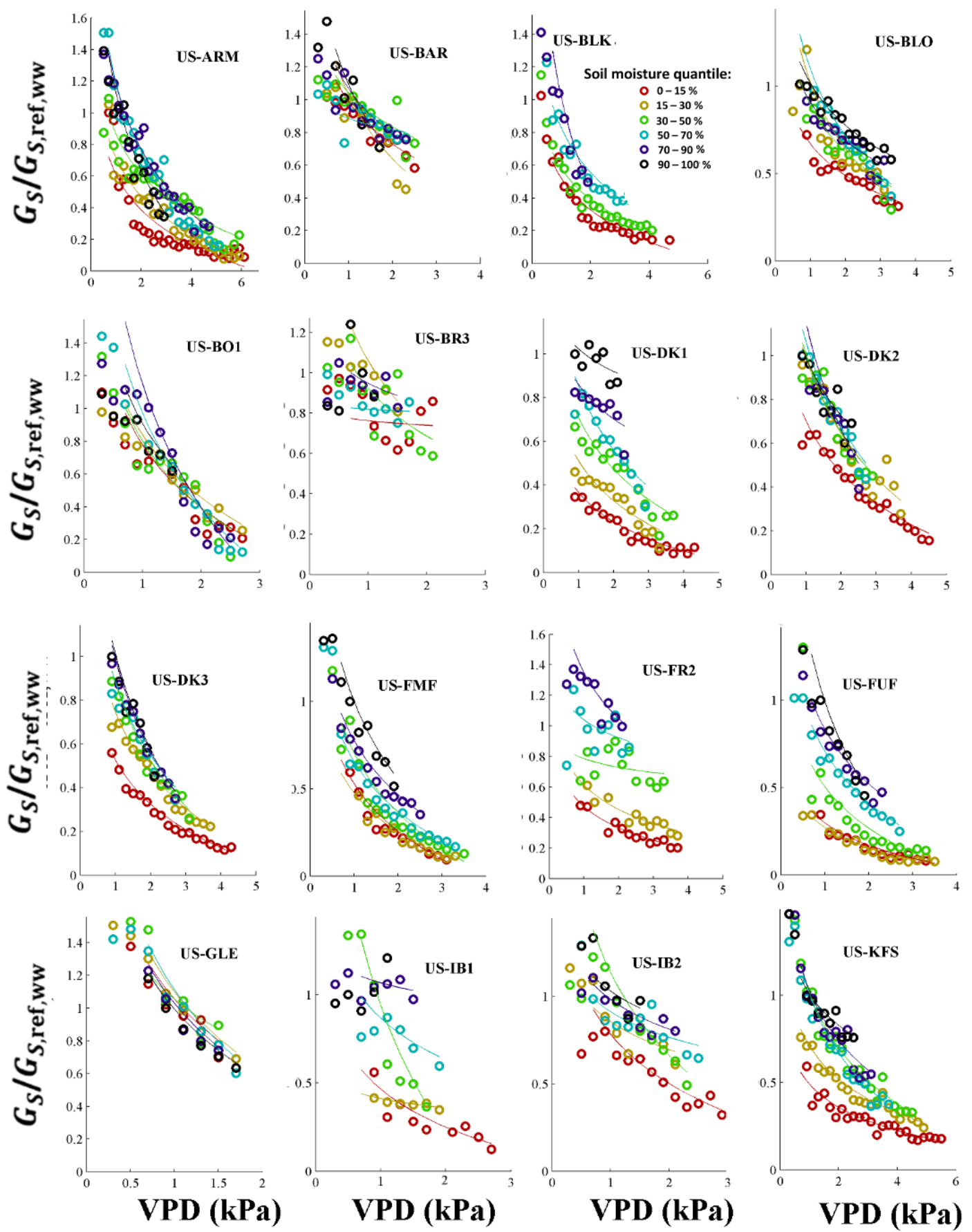

Figure S7. Same as Figure 2a-d in the main text, but for the first sixteen study sites (in alphabetical order). 

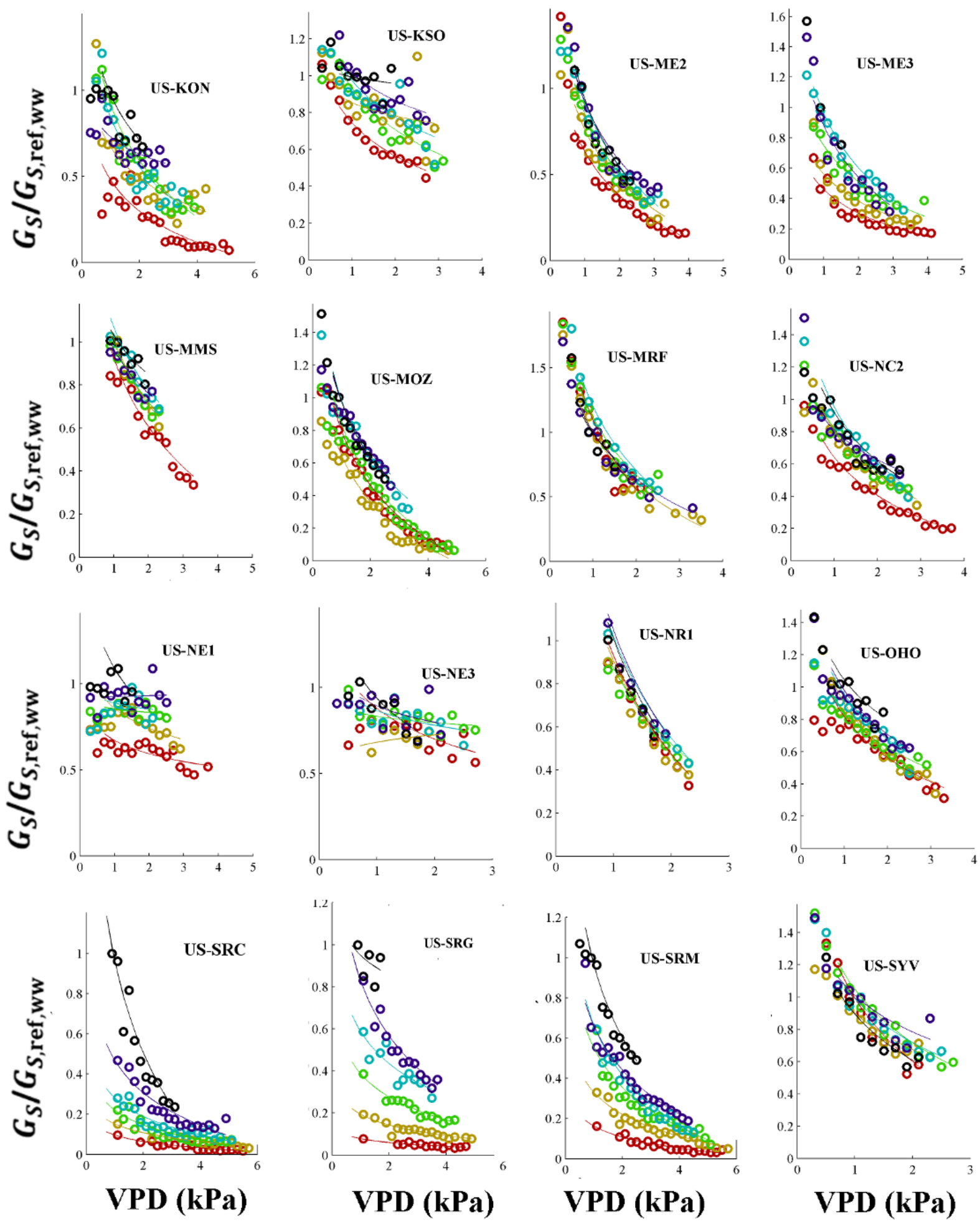

Figure S8. Same as Figure 2a-d in the main text, but for the second sixteen study sites (in alphabetical order). 

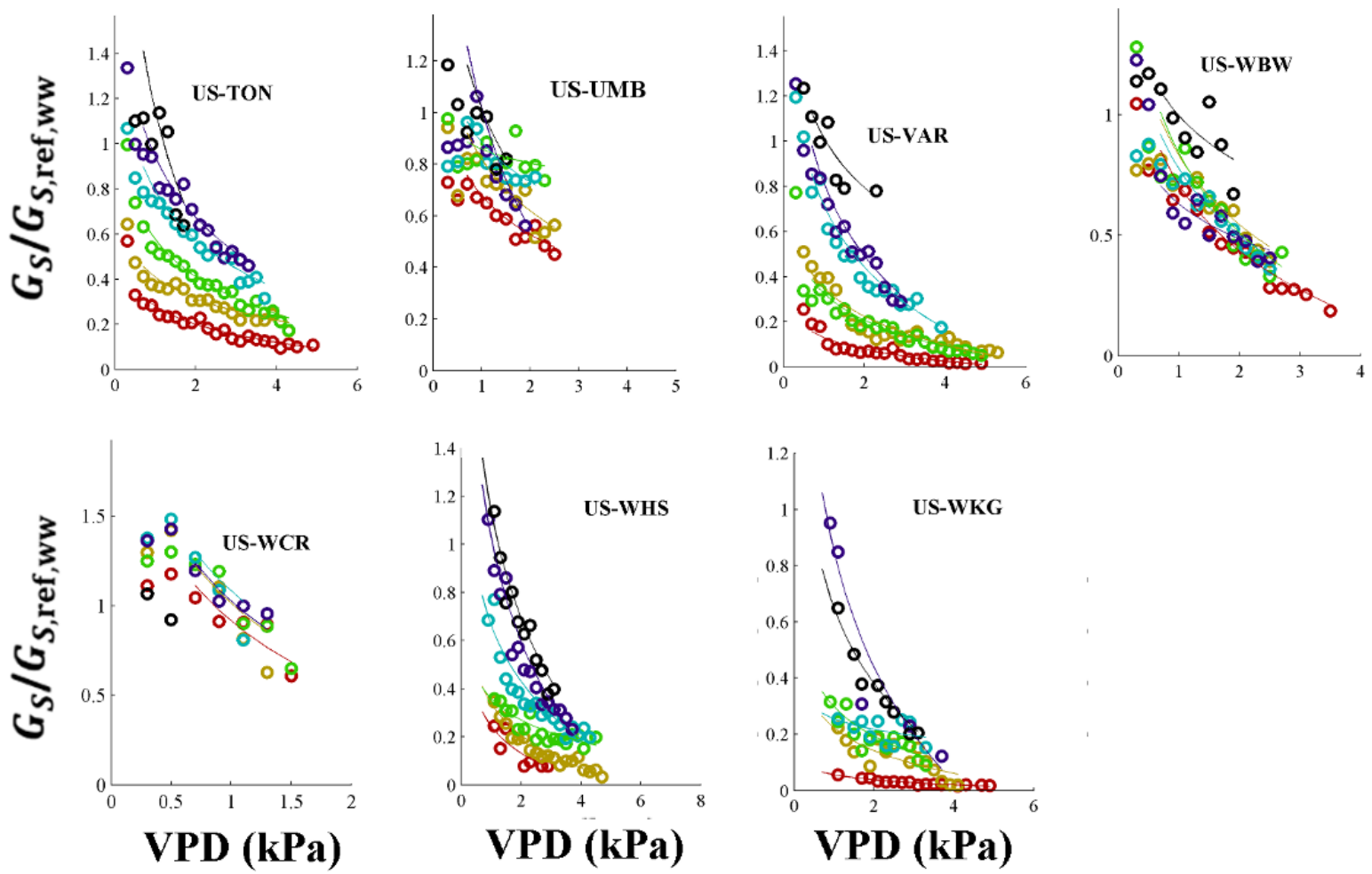

273

274

275

276

277

278

279

280

281

282

283

284

285

286

287

288

289

Figure S9. Same as Figure 2a-d in the main text, but for the last seven study sites (in alphabetical order).

\section{5}

6




\section{Section S7: Effects of other meteorological drivers on $G_{\mathrm{S}, \mathrm{ref}}$}

Other work has demonstrated that the reference surface or stomatal conductance may be sensitive to variations in photosynthetically active radiation (PAR) and air temperature $\left(\mathrm{T}_{\mathrm{a}}\right)^{51,53}$. In this study, variations in $\mathrm{G}_{\mathrm{S}, \text { ref }}$ with PAR or $T_{\mathrm{a}}$ were not explicitly considered, due primarily to the fact that accounting for them (for example, by introducing additional dimensions to the data binning matrix) often results in an insufficient amount of data within each soil moisture bin to properly parameterize Eq. 1 . This is particularly true in sites with a short active season, which include both the hottest and coolest sites in the dataset.

In all sites, $V P D$ is directly correlated with temperature (reflecting the fact that the saturation vapor pressure depends exponentially on $T_{\mathrm{a}}$ ), and also directly correlated with PAR (since $T_{\mathrm{a}}$ tends to be highest when radiation loads are high, see Figure S10). Soil moisture tends to be inversely correlated with $T_{\mathrm{a}}$ in most sites, and only weakly related to PAR (again, see Figure S10).

\section{US-DK3}
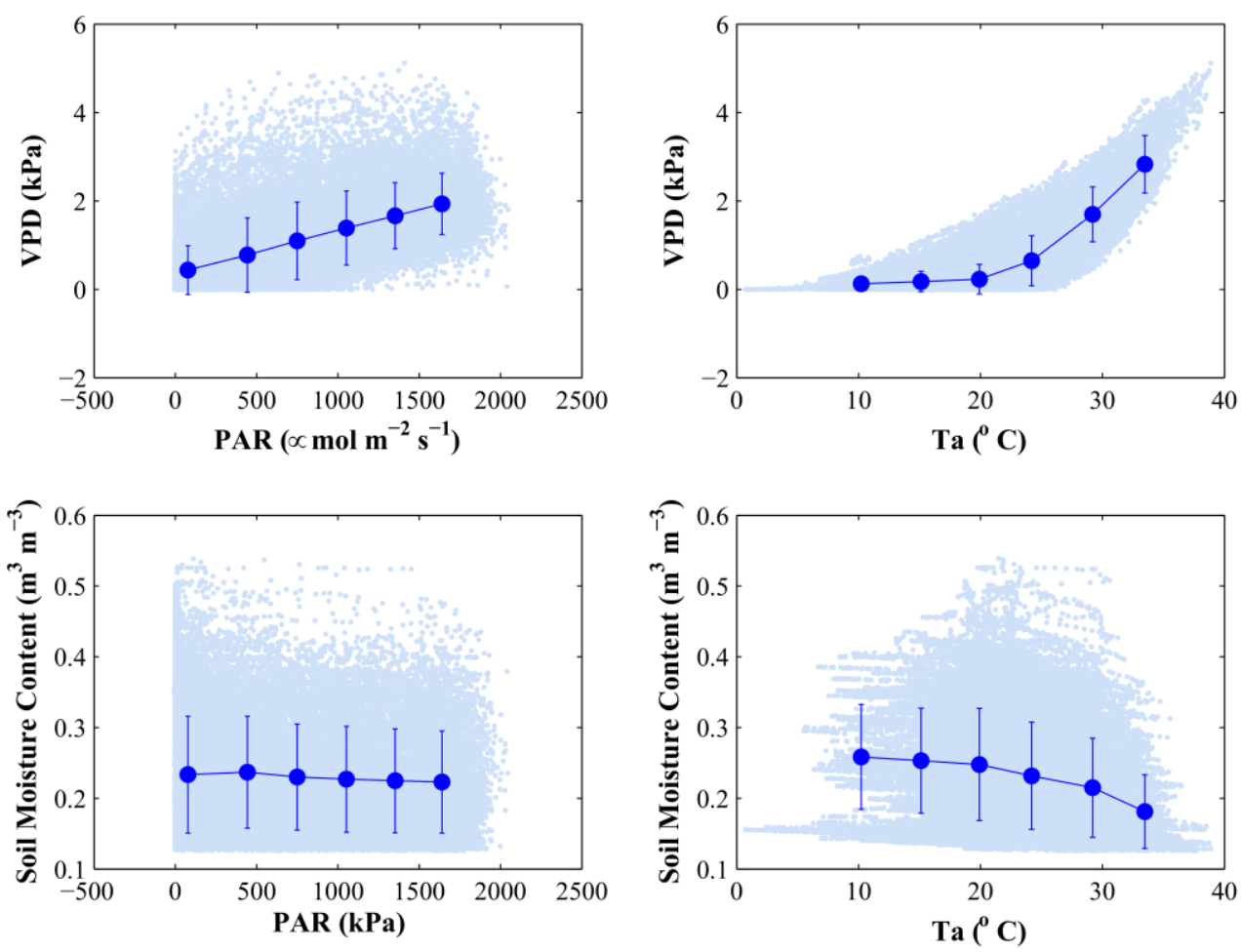

Figure S10: The relationship between vapor pressured deficit (VPD), photosynthetically active radiation (VPD) and air temperature $\left(T_{a}\right)$ at the Duke Forest pine plantation (US-DK3). Light blue dots show all data, and blue circles show binned averages. Error bars show one standard deviation.

It is possible that high $T_{\mathrm{a}}$ may limit $G_{\mathrm{s}}$ and $E T$ through biochemical imitations to leaf-level gas exchange ${ }^{54}$ that occur independent of limitations to $G_{\mathrm{s}}$ imposed by high $V P D$. In that case, failure to resolve temperature effects on $G_{\mathrm{s}}$ could lead us to overestimate the VPD limitations and underestimate the soil moisture limitations. On the other hand, because canopy stomatal conductance is known to be 
311 monotonically related to PAR ${ }^{51,55}$, failure to account for independent PAR effects could lead us to 312 underestimate VPD limitations and overestimate soil moisture limitations.

313 To explore the extent to which these biases are significant, in each site, we attempted separate 314 parameterizations for Eq. 1 when PAR was limited to high values (PAR $>1500 \mu \mathrm{mol} \mathrm{m} \mathrm{s}^{-1}$ ) and when $\mathrm{T}_{\mathrm{a}}$ 315 was limited to a relatively narrow range of $5{ }^{\circ} \mathrm{C}$. In both cases, data were binned according to soil moisture content as described in the methods of the main text. The range of temperature depended on the mean growing season $T_{\mathrm{a}}$ at each site but was usually between 20 and $25^{\circ} \mathrm{C}$. Enough growing season data were available to support this effort in 23 of the sites. In general, the $\mathrm{Gs}_{\text {ref,j }}$ (i.e. $\mathrm{G}_{\mathrm{S}, \mathrm{ref}}$ for each of the $\mathrm{j}=6$ soil moisture bins) were similar regardless of whether the full or filtered datasets were used (see Fig S11 for results from representative sites). Specifically, across all sites, the slope of the relationship between the $\mathrm{Gs}_{\text {ref }}$ values obtained from the full dataset as compared to the dataset filtered to a narrow temperature range was 0.97 on average (st. dev. $=0.44$ ), and the average correlation coefficient was 0.75 . Similarly, the slope of the relationship between the $\mathrm{G}_{\mathrm{S} \text {,ref }}$ values obtained from the full dataset as compared to the dataset filtered to a PAR range was 1.02 on average (std dev. $=0.40$ ), and the average correlation coefficient was 0.80 . Thus, the decision not to account for PAR and $T_{\mathrm{a}}$ effects on $\mathrm{G}_{\mathrm{S} \text {,ref }}$ does not introduce systematic biases across the sites. 

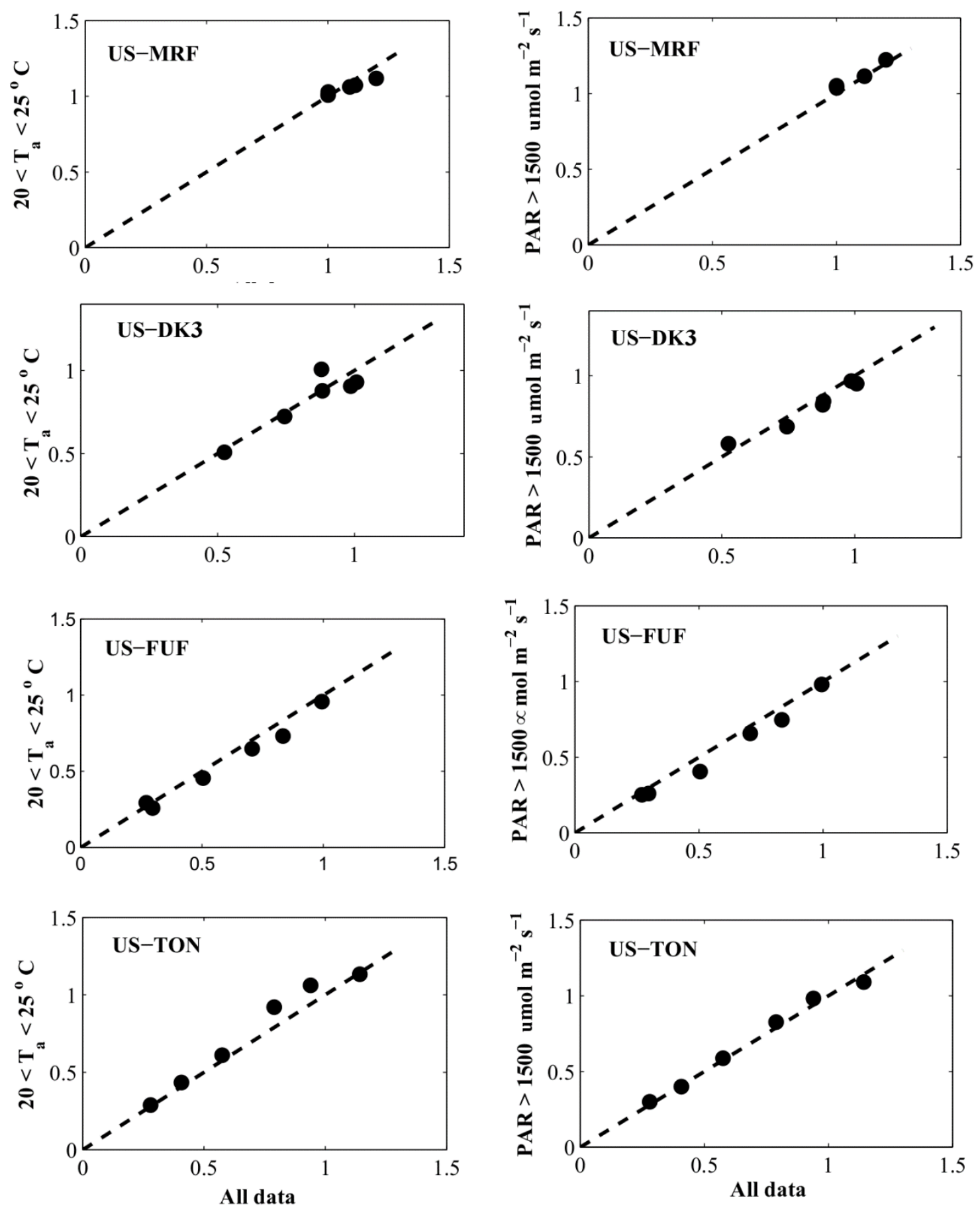

Figure S11: The relationship between the reference $G_{s}$ within each soil moisture bin (i.e. $\left.G_{s, r e f, j}\right)$ as derived from all growing season data (subject to the filtering constraints described in Section S1), and data subjected to an additional temperature filter (left hand column) or PAR filter (right hand column). The sites shown here span a range of dryness index (see Table S1). 


\section{Section S8: Future projections - model estimates and downscaling}

Projections for future meteorological variables, including $R_{\mathrm{n}}, V P D$, air temperature, and precipitation were obtained from ten general circulation models for the period from 2071-2080 (see SI), chosen as the transition point between the mid- and late- $21^{\text {st }}$ century. Modeled data were downscaled in space using parametric approaches, and downscaled in time using representative diurnal patterns measured at each study site. Future soil moisture was estimated from a marginal distribution sampling approach based on short- and long-term dynamics of $V P D$ and precipitation that reproduced observed soil moisture dynamics with little bias. The future VPD and soil moisture limitations to $G_{\mathrm{S}}$ and $E T$ were then determined in a matter analogous to the approach for present day conditions.

Obtaining projections of future meteorological drivers: Estimates of the key drivers of the PenmanMonteith model were obtained from the Multivariate Adaptive Constructed Analogs $\left(\mathrm{MACA}^{56}\right)$ data warehouse (http://maca.northwestknowledge.net/) for a representative selection of twelve Ameriflux sites that include the long-running towers and that span a wide gradient in climate (See Table S1). Specifically, a daily time series of net radiation, air temperature, specific humidity, and wind speed projected from 10 General Circulation Models from the Coupled Model Intercomparison Project - Phase 5 (CMIP5) archive driven by representative concentration pathway 8.5 (highest greenhouse gas emission scenario) were downloaded for the period 1950-2099. The ten models are listed in Table S3.

Table S3: The models used to obtain estimates of future meteorological drivers

\begin{tabular}{|c|c|c|}
\hline Model Name & Model Country & Model Agency \\
\hline$\underline{\text { CanESM2 }}$ & Canada & $\begin{array}{l}\text { Canadian Centre for Climate Modeling and } \\
\text { Analysis }\end{array}$ \\
\hline CNRM-CM5 & France & $\begin{array}{l}\text { National Centre of Meteorological Research, } \\
\text { France }\end{array}$ \\
\hline CSIRO-Mk3-6-0 & Australia & $\begin{array}{l}\text { Commonwealth Scientific and Industrial } \\
\text { Research Organization/Queensland Climate } \\
\text { Change Centre of Excellence, Australia }\end{array}$ \\
\hline GFDL-ESM2G & USA & $\begin{array}{l}\text { NOAA Geophysical Fluid Dynamics } \\
\text { Laboratory, USA }\end{array}$ \\
\hline HadGEM2-ES & United Kingdom & Met Office Hadley Center, UK \\
\hline inmem4 & Russia & Institute for Numerical Mathematics, Russia \\
\hline IPSL-CM5A-LR & France & Institut Pierre Simon Laplace, France \\
\hline MIROC-ESM-CHEM & Japan & $\begin{array}{l}\text { Japan Agency for Marine-Earth Science and } \\
\text { Technology, Atmosphere and Ocean Research } \\
\text { Institute (The University of Tokyo), and } \\
\text { National Institute for Environmental Studies }\end{array}$ \\
\hline$\underline{\text { MIROC5 }}$ & Japan & $\begin{array}{l}\text { Atmosphere and Ocean Research Institute (The } \\
\text { University of Tokyo), National Institute for } \\
\text { Environmental Studies, and Japan Agency for } \\
\text { Marine-Earth Science and Technology }\end{array}$ \\
\hline
\end{tabular}

Spatial downscaling of the model data: While the MACA CMIP data have already been downscaled with respect to the climate models, the spatial resolution of these data $(4 \mathrm{~km} \mathrm{x} 4 \mathrm{~km})$ still exceeds the size of a typical flux footprint (typically $<1$ square $\mathrm{km}$ during the daytime). Furthermore, significant biases were observed between the CMIP and observed meteorological drivers. Thus, the meteorological data were further downscaled using a parametric approach driven by the site-level observations. 
Specifically, for air temperature, $V P D, R_{\mathrm{n}}$, and wind speed, histograms of the downscaled GCM data for the period coincident with the study period at each site were compared to histograms of the measured data after the latter was aggregated to daily averages to match the temporal resolution of the modeled data. Biases were removed by first log-transforming both datasets, and then determining the mean and standard deviation of the resulting log-normal distributions. The modeled time series were then further transformed to a standard log-normal variable that was then scaled using the mean and standard deviation of the logtransformed measured time series, and exponentiated (hereafter the "modeled ${ }_{\text {present,scaled" data). This }}$ downscaling was performed separately for each model.

Next, the modeled meteorological time series for the period 2071-2080 were extracted as representative of the mid-to-late $21^{\text {st }}$ century. The shift in the mean of each modeled variable between the measurement ("present") time period and the future was determined from the unscaled daily projections according to:

$\mu_{\text {factor }}=\left(\frac{\operatorname{mean}\left[\ln \left(\operatorname{modeled}_{2071-2080}\right)\right]}{\text { mean }\left[\ln \left(\operatorname{modeled}_{\text {present }}\right)\right]}\right)$

$\sigma_{\text {factor }}=\left(\frac{\operatorname{stdev}\left[\ln \left(\operatorname{modeled}_{2071-2080}\right)\right]}{\operatorname{stdev}\left[\ln \left(\operatorname{modeled}_{\text {present }}\right)\right]}\right)$

The time series for the period 2071-2080 was then transformed into a standard normal variable that was then scaled using the mean and standard deviation of the modeled $_{\text {present,scaled }}$ distributions after correcting those moments by $\mu$-fac and $\sigma$-fac, respectively. This approach preserves the projected relative changes in the mean and variance of the modeled time series between the present and future conditions, but retains the spatial downscaling to the site level.

Projecting future relative extractable soil water: Projections of downscaled soil moisture were not available from the MACA data warehouse. Efforts to project future soil moisture by using process-based modeled estimates of $E T$ and precipitation are not aligned with the goals of this study, which are to determine how variations in soil moisture and VPD affect estimates of ET (i.e. such an analysis would be circular). Thus, future soil moisture (at a daily time step) was estimated using a site-specific marginal distribution sampling approach (i.e. a look-up table), similar to the approaches frequently used to gapfill missing eddy covariance data ${ }^{57}$. Accordingly, measured $\theta$ data were binned according to the following classification scheme, which depends on the total time since a significant rain event $(>20 \mathrm{~mm})$, among other hydrologic variables:

1) If the time since a significant ( $>20 \mathrm{~mm}$ ) rain event is less than two days, then soil moisture is the mean of measured values when:

- The total precipitation within the last 7 days agrees to within $10 \mathrm{~mm}$

- The day-of-year agrees to within 10 days;

else, 2) If the time since a significant ( $>20 \mathrm{~mm}$ ) rain event is between 2 and 3 days, then soil moisture is the mean of measured values when:

- The total precipitation within the last 30 days agrees to $20 \mathrm{~mm}$

- The total precipitation within the last 7 days agrees to $10 \mathrm{~mm}$

- The mean VPD within the last 30 days agrees to within $0.15 \mathrm{kPa}$

- The day-of-year agrees to within 10 days;

else, 3) If the time since a significant (>20 mm) rain event is greater than three days, then soil moisture is the mean of measured values when:

- The time since a significant rain event agrees to within 5 days

- The total precipitation within the last 30 days agrees to $20 \mathrm{~mm}$

- The total precipitation within the last 7 days agrees to $10 \mathrm{~mm}$

- The mean VPD within the last 30 days agrees to within $0.15 \mathrm{kPa}$ 
401 Most of the data fall into category three. We found that it was sometimes necessary to iteratively relax the 402 search criteria in order to obtain at least two observations of soil moisture that match the criteria for every 403 hourly or half-hour observation in the record. Specifically, for category three data, the criteria were 404 loosened as follows:

405

406

407

408

409

410

411

412

413

414

415

416

417

418

419

420

421

422

423

424

425

426

427

428

429

430

\section{ITERATION 2:}

- The time since a significant rain event agrees to within 8 days

- The total precipitation within the last 30 days agrees to $30 \mathrm{~mm}$

- The total precipitation within the last 7 days agrees to $20 \mathrm{~mm}$

- The mean VPD within the last 30 days agrees to within $.25 \mathrm{kPa}$

- The Julian day of year agrees to within 20 days

\section{ITERATION 3:}

- The time since a significant rain event agrees to within 10 days

- The total precipitation within the last 30 days agrees to $40 \mathrm{~mm}$

- The total precipitation within the last 7 days agrees to $30 \mathrm{~mm}$

- The mean VPD within the last 30 days agrees to within $0.4 \mathrm{kPa}$

- The day-of-year agrees to within 180 days

\section{ITERATION 4:}

- The mean VPD within the last 30 days agrees to within $0.4 \mathrm{kPa}$

Any remaining gaps in the modeled $\theta$ record were linearly interpreted.

In general, the marginal distribution sampling approach reproduced measured $\theta$ time series very well. A representative case is shown in Figure S10 and S11 for US-DK3, the Duke Pine Forest Site. Figure S12 shows the slope and correlation coefficient $\left(r^{2}\right)$ between the measured and modeled $\theta$ for all sites used in this portion of the analysis. Biases in the slope were less than $5 \%$ in most sites, and correlation was generally between 0.8 and 1.0 . 

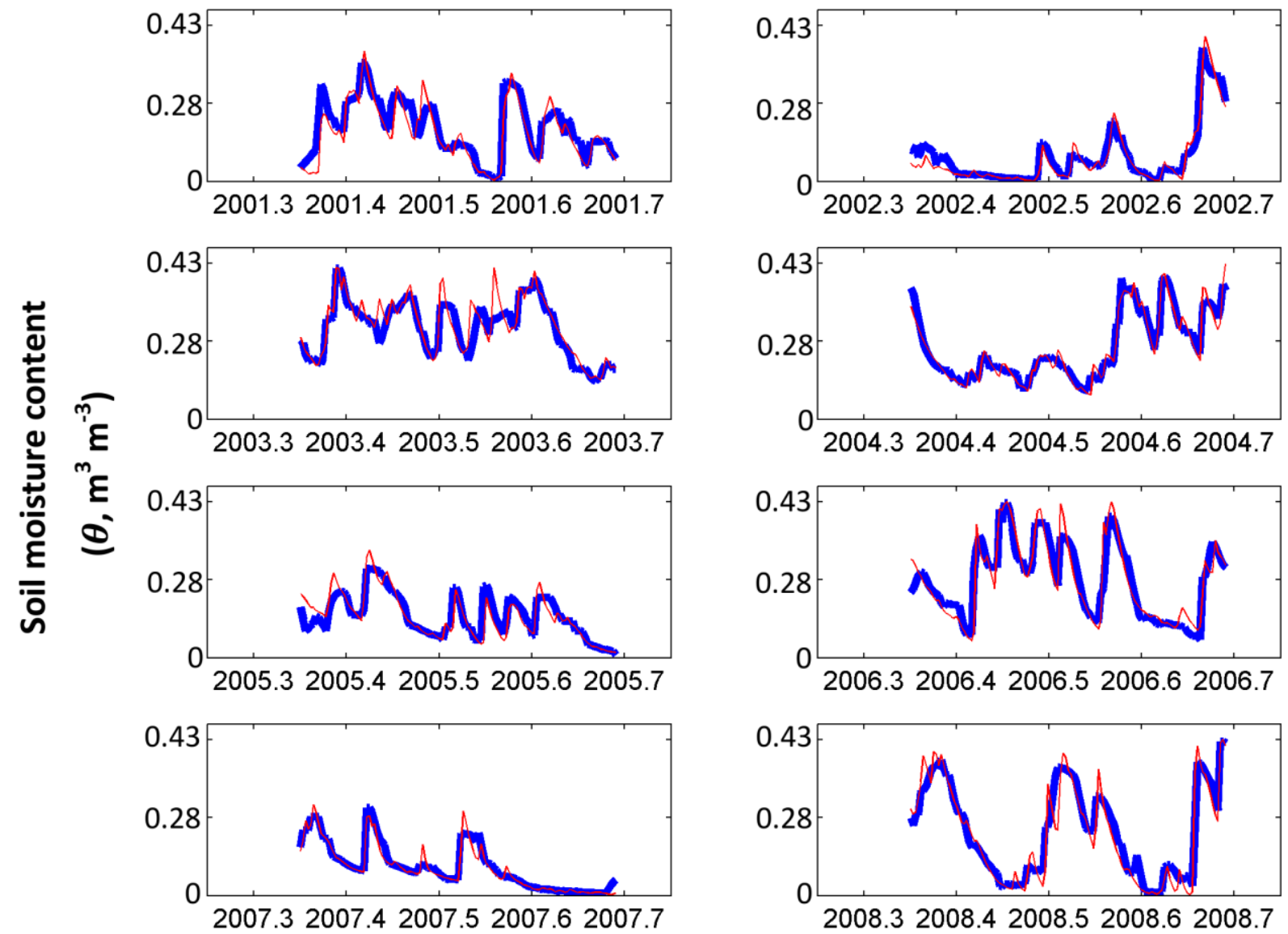

431

432

433

434
Figure S10: The measured (red) and modeled (blue line) trends in growing season, daily-averaged soil moisture content $(\theta)$ for the eight site-years of data available from the Duke Pine Forest Site (US-DK3). 


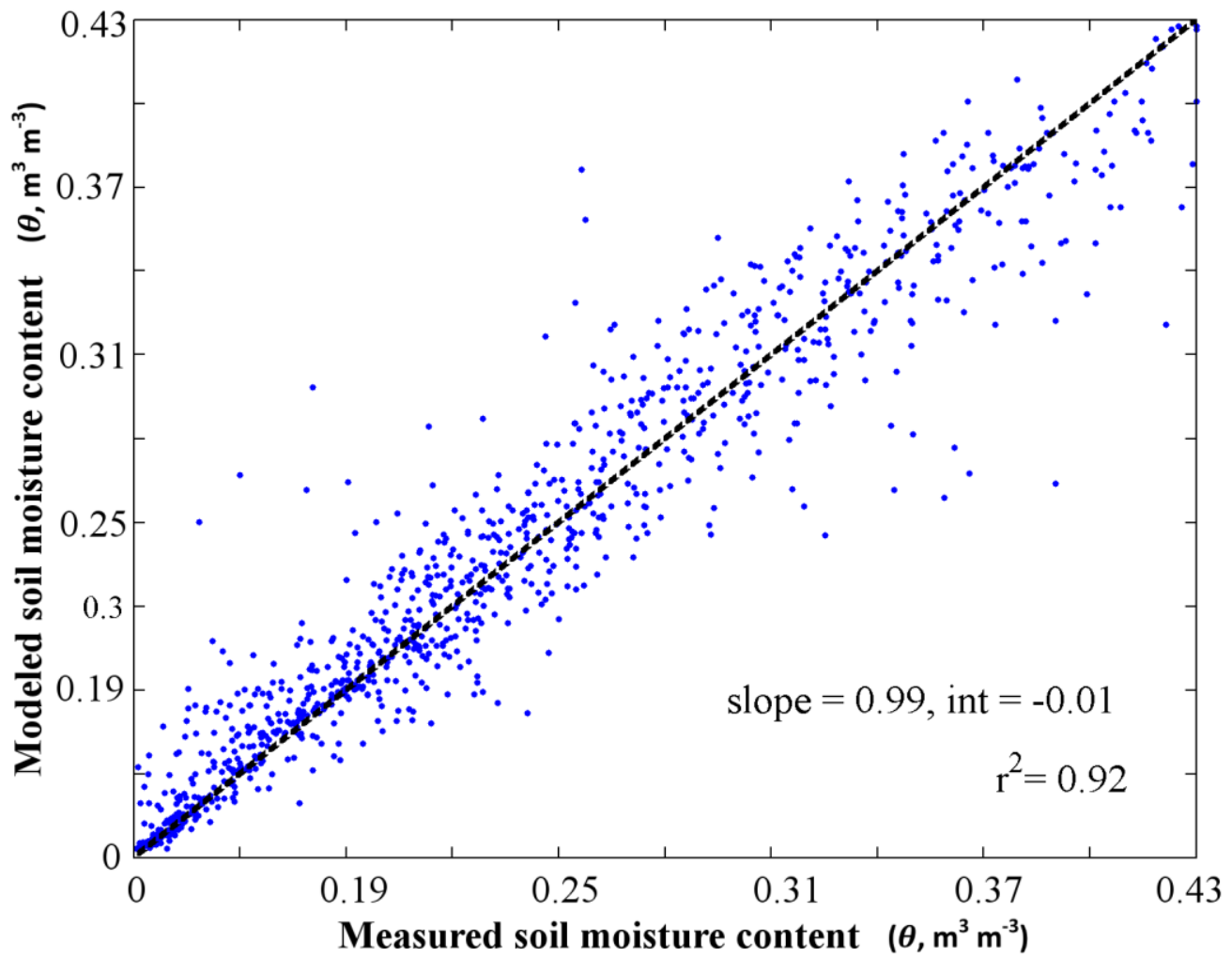

435

436

437

438

439

440

441

442
Figure S11: The 1:1 comparison between modeled and measured daily REW in the Duke Forest Pine Site (US-DK 3). 

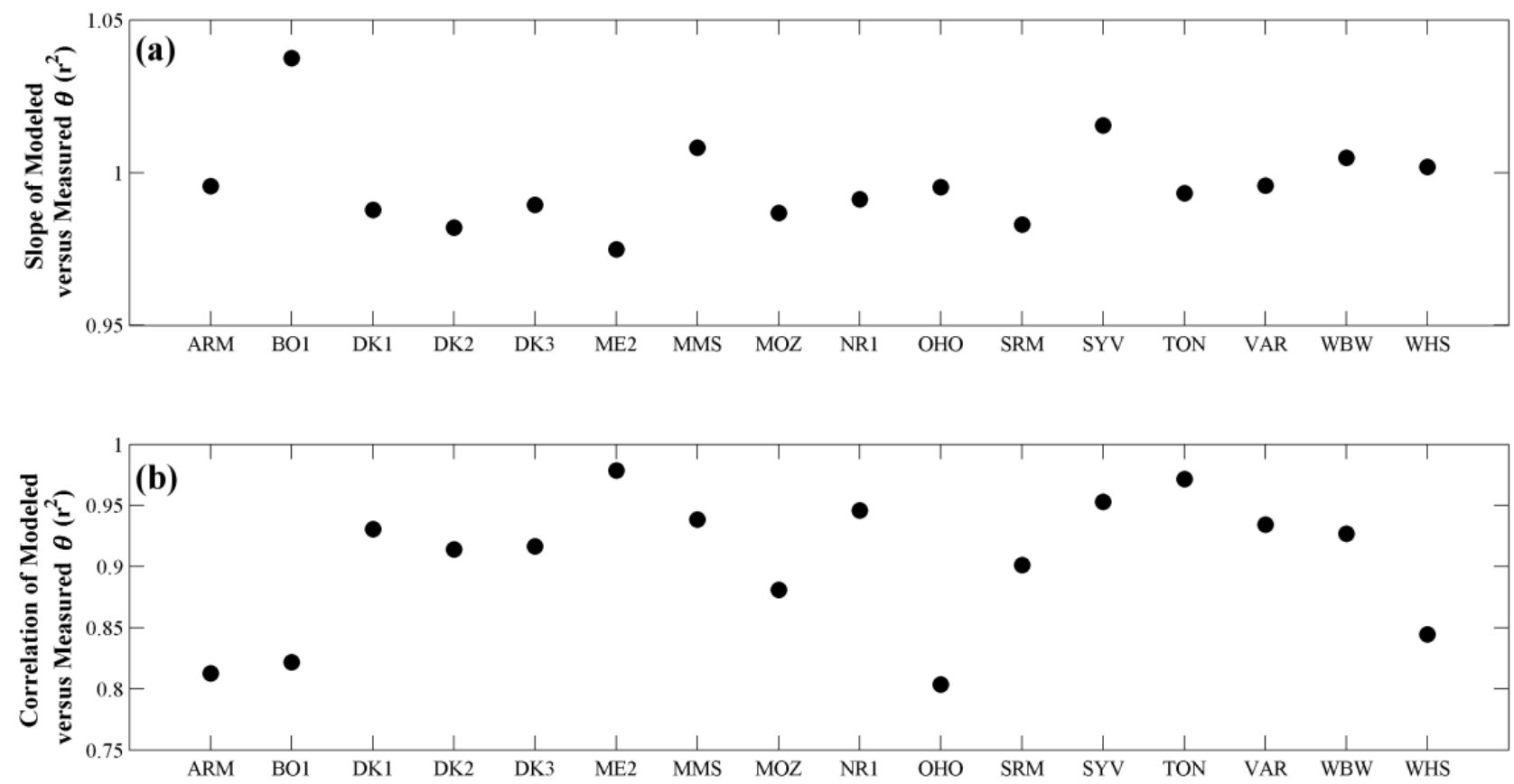

444 Figure S12: The slope (top panel) and correlation coefficient (bottom panel) between modeled and 445 measured soil moisture content across all of the sites included in the analysis of future limitations to 446 surface conductance and ET.

Future changes in key meteorological drivers: The following figures (Figure S13-16) show the present and projected future means for the key drivers of the Penman-Monteith equation. Nearly all models project increases in future $V P D$ in all sites relative to present, occurring concurrently with projected increases in air temperature $\left(T_{\mathrm{a}}\right)$. Projected changes in net radiation $\left(R_{\mathrm{n}}\right)$ and wind speed $(U)$ are relatively small. Models tend to agree on the change in $\theta$ at each site, although across sites no clear trends emerged 453 (i.e., it increases in some, but decreases in others).

454 Because it is important to preserve the coupling between precipitation and $V P D$ when determining how soil moisture and $V P D$ limit ET, the models were not ensemble averaged. Rather, each of the ten models was used to quantify the limitation to future $E T$ from soil moisture and $V P D$, and these limitations were then ensemble averaged across the model runs. 

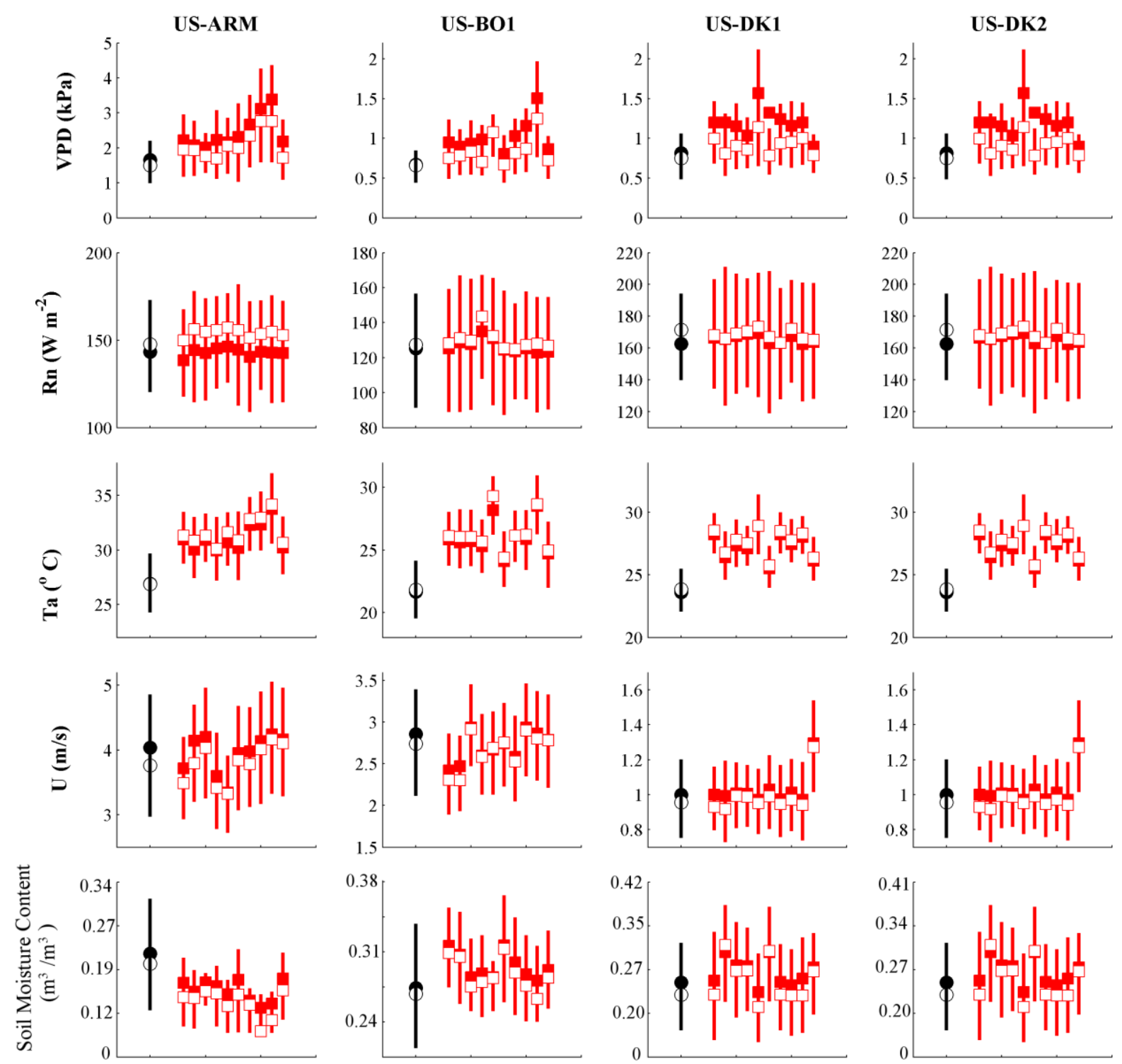

Figure S13: The mean (filled symbols) and median (open symbols) daytime growing season value for key meteorological drivers for present climate conditions (black symbols, derived from Ameriflux observations) and the future (red symbols, derived from model predictions) for select study sites. Error bars show the 50\% range daytime values of each variable, and are expected to overlap as these meteorological drivers experience wide shifts over the course of a day and the course of the growing season. The future data and associated error lines are associated with the ten models of Table S3, in sequential order. 

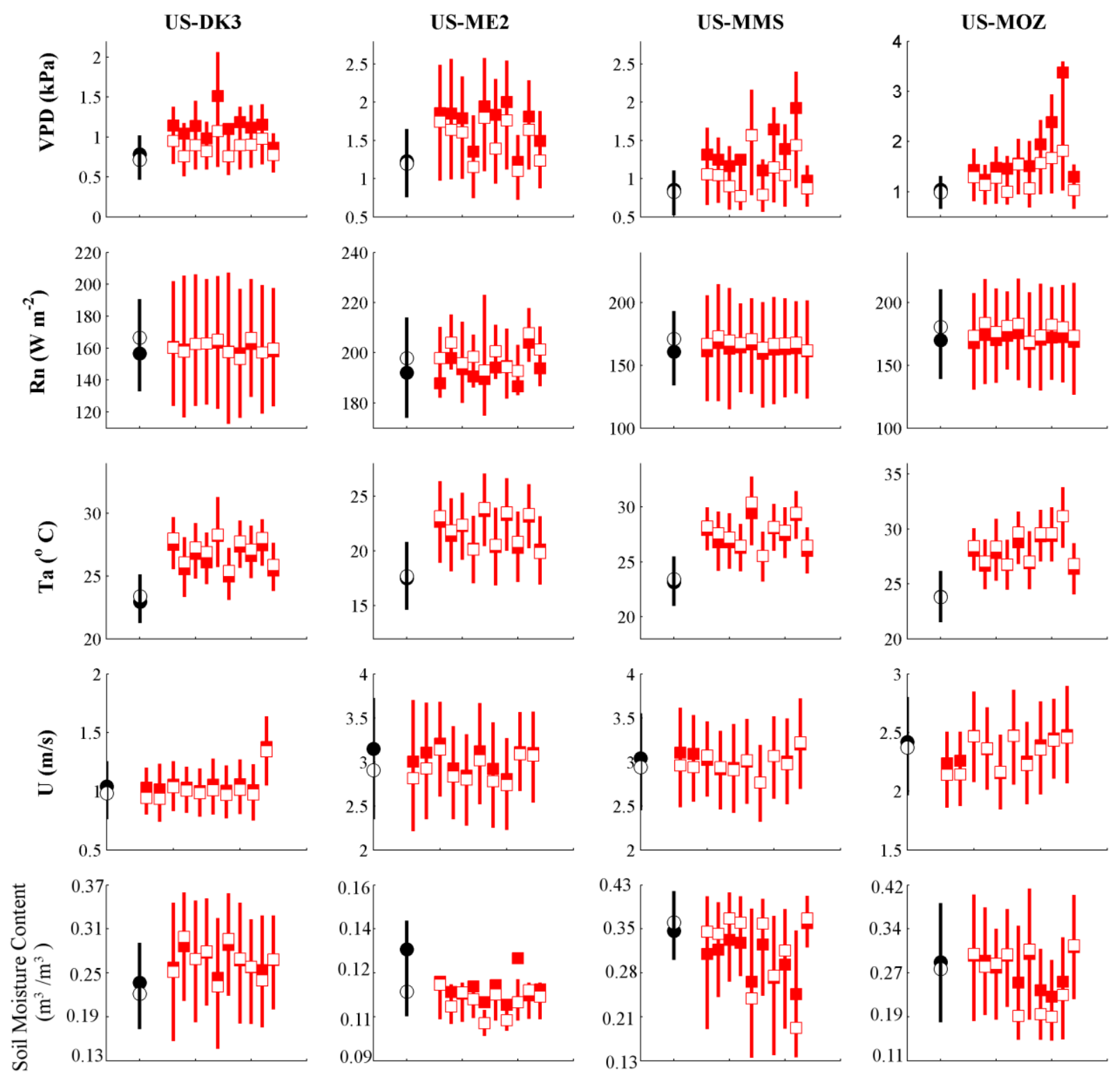

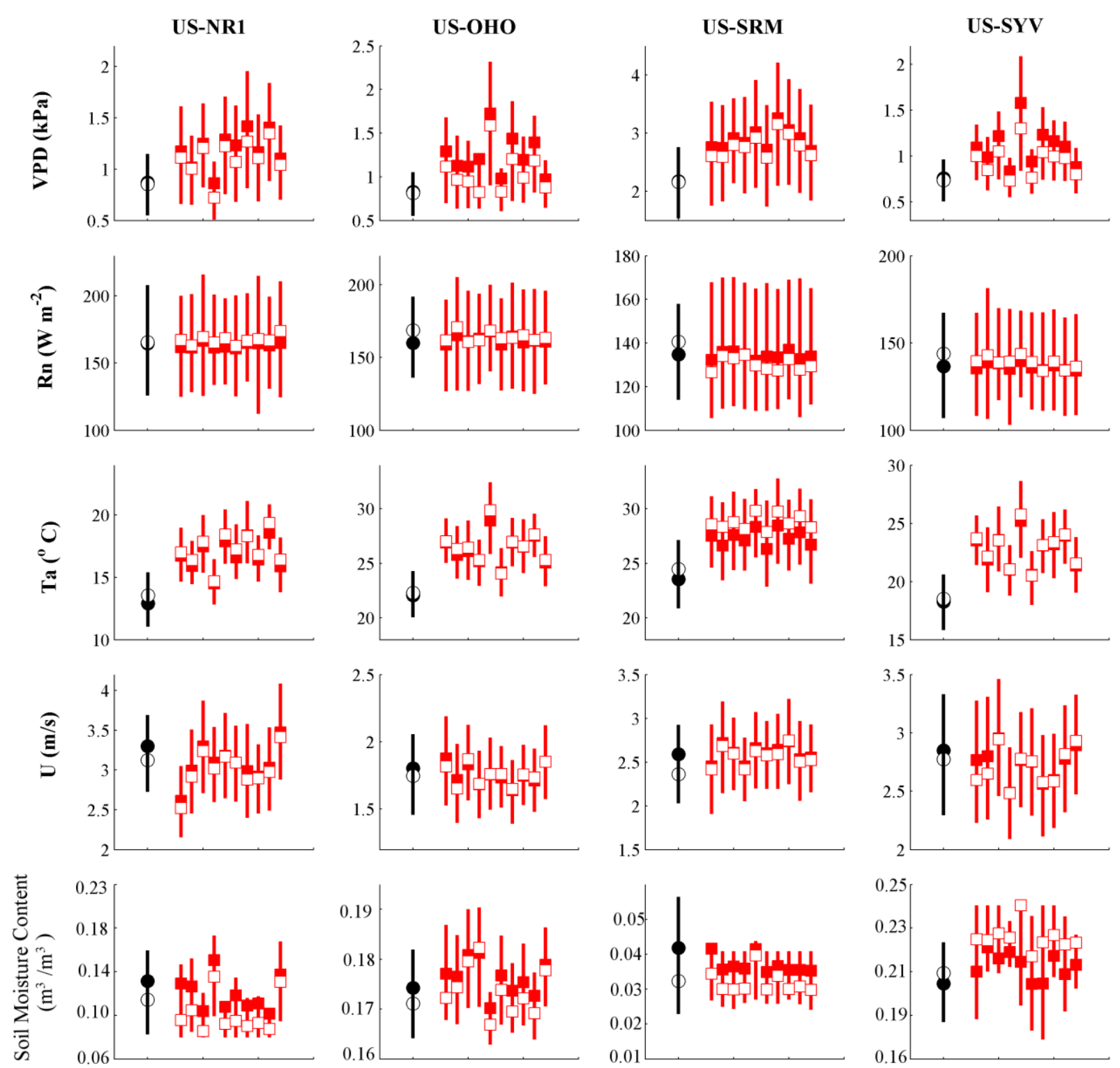

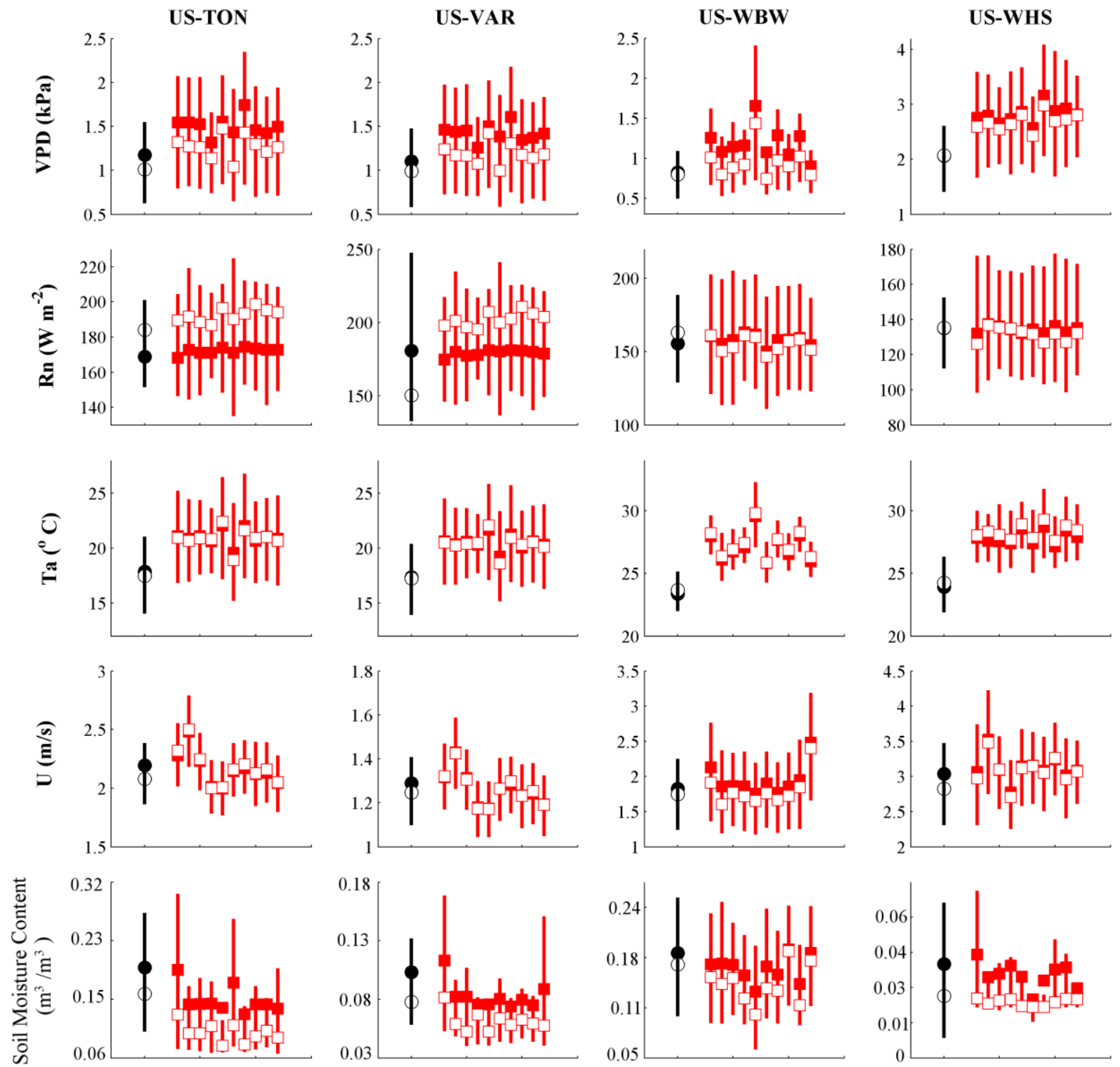

Figure S16: Same as Figure 15, but for additional sites 


\section{Works Cited in the Supplementary Information:}

1. Fischer ML, Billesbach DP, Berry JA, Riley WJ, Torn MS. Spatiotemporal variations in growing season exchanges of $\mathrm{CO}_{2}, \mathrm{H} 2 \mathrm{O}$, and sensible heat in agricultural fields of the Southern Great Plains. Earth Interactions 2007, 11: DOI: 10.1175/EI231.1.

501

502

503

504

505

506

507

508

509

510

511

512

513

514

515

516

517

518

519

520

521

522

523

524

525

526

527

528

529

530

531

532

533
2. Jenkins JP, Richardson AD, Braswell BH, Ollinger SV, Hollinger DY, Smith ML. Refining lightuse efficiency calculations for a deciduous forest canopy using simultaneous tower-based carbon flux and radiometric measurements. Agricultural and Forest Meteorology 2007, 143(1-2): 64-79.

3. Goldstein A, Hultman N, Fracheboud J, Bauer M, Panek J, Xu M, et al. Effects of climate variability on the carbon dioxide, water, and sensible heat fluxes above a ponderosa pine plantation in the Sierra Nevada (CA). Agricultural and Forest Meteorology 2000, 101(2): 113129.

4. Meyers TP, Hollinger SE. An assessment of storage terms in the surface energy balance of maize and soybean. Agricultural and Forest Meteorology 2004, 125(1-2): 105-115.

5. Hernandez-Ramirez G, Hatfield JL, Parkin TB, Sauer TJ, Prueger JH. Carbon dioxide fluxes in corn-soybean rotation in the midwestern US: Inter- and intra-annual variations, and biophysical controls. Agricultural and Forest Meteorology 2011, 151(12): 1831-1842.

6. Novick KA, Oishi AC, Ward EJ, Siqueira MBS, Juang JY, Stoy PC. On the difference in the net ecosystem exchange of $\mathrm{CO}_{2}$ between deciduous and evergreen forests in the southeastern U.S. Global Change Biology 2015, 21: 827-842. .

7. Stoy PC, Katul GG, Siqueira MBS, Juang JY, Novick KA, McCarthy HR, et al. Role of vegetation in determining carbon sequestration along ecological succession in the southeastern United States. Global Change Biology 2008, 14(6): 1409-1427.

8. Allison VJ, Miller RM, Jastrow JD, Matamala R, Zak DR. Changes in soil microbial community structure in a tallgrass prairie chronosequence. Soil Science Society of America Journal 2005, 69(5): 1412-1421.

9. Dore S, Kolb TE, Montes-Helu M, Eckert SE, Sullivan BW, Hungate BA, et al. Carbon and water fluxes from ponderosa pine forests disturbed by wildfire and thinning. Ecological Applications 2010, 20(3): 663-683. 
10. Heinsch F, Heilman J, McInnes K, Cobos D, Zuberer D, Roelke D. Carbon dioxide exchange in a high marsh on the Texas Gulf Coast: effects of freshwater availability. Agricultural and Forest Meteorology 2004, 125(1): 159-172.

11. Musselman R, Massman W, Frank J, Korfmacher J. The temporal dynamics of carbon dioxide under snow in a high elevation Rocky Mountain subalpine forest and meadow. Arctic, antarctic, and alpine research 2005, 37(4): 527-538.

12. Brunsell N, Nippert J, Buck T. Impacts of seasonality and surface heterogeneity on water-use efficiency in mesic grasslands. Ecohydrology 2014, 7(4): 1223-1233.

13. Scott, R.L., Biederman, J.A., Hamerlynck, E.P. and Barron-Gafford, G.A. 2015. The carbon balance pivot point of southwestern U.S. semiarid ecosystems: Insights from the 21st century drought. Journal of Geophysical Research: Biogeosciences, 120, 2612-2624. doi: 10.1002/2015JG003181.

14. Thomas CK, Martin JG, Law BE, Davis K. Toward biologically meaningful net carbon exchange estimates for tall, dense canopies: Multi-level eddy covariance observations and canopy coupling regimes in a mature Douglas-fir forest in Oregon. Agricultural and Forest Meteorology 2013, 173: $14-27$.

15. Verma SB, Dobermann A, Cassman KG, Walters DT, Knops JM, Arkebauer TJ, et al. Annual carbon dioxide exchange in irrigated and rainfed maize-based agroecosystems. Agricultural and Forest Meteorology 2005, 131(1): 77-96.

16. Campbell J, Sun O, Law B. Supply-side controls on soil respiration among Oregon forests. Global Change Biology 2004, 10(11): 1857-1869.

17. Vickers D, Thomas C, Law BE. Random and systematic CO 2 flux sampling errors for tower measurements over forests in the convective boundary layer. Agricultural and Forest Meteorology 2009, 149(1): 73-83.

18. Gu L, Pallardy S, Hosman K, Sun Y. Drought-influenced mortality of tree species with different predawn leaf water dynamics in a decade-long study of a central US forest. Biogeosciences 2015, 12(10): 2831-2845.

19. Seco R, Karl T, Guenther A, Hosman KP, Pallardy SG, Gu L, et al. Ecosystem-scale VOC fluxes during an extreme drought in a broad-leaf temperate forest of the Missouri Ozarks (central USA). Global Change Biology 2015, 21: 3657-3674.

20. Roman DT, Novick KA, Brzostek ER, Dragoni D, Rahman AF, Phillipps R. The role of isohydric and anisohydric species in determining ecosystem-scale response to severe drought. Oecologia 2015, 179(3): 641-654. 
603

604

605

606

607

608

609

610

611

612

613

614

615

616

617

21. Noomets A, Gavazzi MJ, McNulty SG, Domec J-C, Sun G, King JS, et al. Response of carbon fluxes to drought in a coastal plain loblolly pine forest. Global Change Biology 2009, 16: 272287.

22. Monson R, Turnipseed A, Sparks J, Harley P, Scott-Denton L, Sparks K, et al. Carbon sequestration in a high-elevation, subalpine forest. Global Change Biology 2002, 8(5): 459-478.

23. DeForest JL, Noormets A, McNulty SG, Sun G, Tenney G, Chen J. Phenophases alter the soil respiration-temperature relationship in an oak-dominated forest. International Journal of Biometeorology 2006, 51(2): 135-144.

24. Sanchez-Mejia ZM, Papuga SA. Observations of a two-layer soil moisture influence on surface energy dynamics and planetary boundary layer characteristics in a semiarid shrubland. Water Resources Research 2014, 50(1): 306-317.

25. Desai AR, Bolstad PV, Cook BD, Davis KJ, Carey EV. Comparing net ecosystem exchange of carbon dioxide between an old-growth and mature forest in the upper Midwest, USA. Agricultural and Forest Meteorology 2005, 128(1-2): 33-55.

26. Ma S, Baldocchi DD, Xu L, Hehn T. Inter-annual variability in carbon dioxide exchange of an oak/grass savanna and open grassland in California. Agricultural and Forest Meteorology 2007, 147(3): 157-171.

27. Curtis PS, Hanson PJ, Bolstad P, Barford C, Randolph J, Schmid H, et al. Biometric and eddycovariance based estimates of annual carbon storage in five eastern North American deciduous forests. Agricultural and Forest Meteorology 2002, 113(1): 3-19.

28. Verma SB, Baldocchi DD, Anderson DE, Matt DR, Clement RJ. Eddy fluxes of $\mathrm{CO}_{2}$, water vapor, and sensible heat over a deciduous forest. Boundary-Layer Meteorology 1986, 36(1-2): 71-91.

29. McDowell N, Barnard H, Bond BJ, Hinckley T, Hubbard RM, Ishii H, et al. The relationship between tree height and leaf area: sapwood area ratio. Oecologia 2002, 132(1): 12-20.

30. Novick K, Oren R, Stoy P, Juang JY, Siqueira M, Katul G. The relationship between reference canopy conductance and simplified hydraulic architecture. Advances in Water Resources 2009, 32(6): 809-819.

31. Oren R, Sperry JS, Katul GG, Pataki DE, Ewers BE, Phillips N, et al. Survey and synthesis of intra- and interspecific variation in stomatal sensitivity to vapour pressure deficit. Plant Cell Environ 1999, 22(12): 1515-1526. 
628

629

630

631

632

633

634

635

636

637

638

639

640

641

642

643

644

645

646

647

648

649

650

651

652

653

654

655

656

657

658

659

32. Williams CA, Reichstein M, Buchmann N, Baldocchi D, Beer C, Schwalm C, et al. Climate and vegetation controls on the surface water balance: Synthesis of evapotranspiration measured across a global network of flux towers. Water Resources Research 2012, 48(6).

33. Penman HL. Natural Evaporation from Open Water, Bare Soil and Grass. Proceedings of the Royal Society of London Series a-Mathematical and Physical Sciences 1948, 193(1032): 120-\&.

34. Monteith JL. Evaporation and environment. In: Fogg BD (ed). The State and Movement of water in Living Organisms, Symposium of the Society of Experimental Biology, vol. 19. Cambridge University Press: Cambridge, 1965, pp 205-234.

35. Yan H, Wang S, Billesbach D, Oechel W, Zhang J, Meyers T, et al. Global estimation of evapotranspiration using a leaf area index-based surface energy and water balance model. Remote sensing of environment 2012, 124: 581-595.

36. Wilson KB, Hanson PJ, Mulholland PJ, Baldocchi DD, Wullschleger SD. A comparison of methods for determining forest evapotranspiration and its components: sap-flow, soil water budget, eddy covariance and catchment water balance. Agricultural and Forest Meteorology 2001, 106(2): 153-168.

37. Scanlon TM, Kustas WP. Partitioning evapotranspiration using an eddy covariance-based technique: Improved assessment of soil moisture and land-atmosphere exchange dynamics. Vadose Zone Journal 2012, 11(3).

38. Wang L, Niu S, Good SP, Soderberg K, McCabe MF, Sherry RA, et al. The effect of warming on grassland evapotranspiration partitioning using laser-based isotope monitoring techniques. Geochimica Et Cosmochimica Acta 2013, 111: 28-38.

39. Oishi AC, Oren R, Novick KA, Palmroth S, Katul GG. Interannual Invariability of Forest Evapotranspiration and Its Consequence to Water Flow Downstream. Ecosystems 2010, 13(3): 421-436.

40. Sulman BN, Roman DT, Scanlon TM, Wang L, Novick KA. Comparing methods for partitioning a decade of carbon dioxide and water vapor fluxes in a temperate forest. Agricultural and Forest Meteorology 2016, In press.

41. Baldocchi D, Meyers T. On using eco-physiological, micrometeorological and biogeochemical theory to evaluate carbon dioxide, water vapor and trace gas fluxes over vegetation: a perspective. Agricultural and Forest Meteorology 1998, 90(1): 1-25.

42. Schulze E-D, Kelliher FM, Korner C, Lloyd J, Leuning R. Relationships among maximum stomatal conductance, ecosystem surface conductance, carbon assimilation rate, and plant 
668

669

670

671

672

673

674

675

676

677

678

679

680

681

682

683

684

685

686

687

688

689

690

691

692

693

694

695

696

697

698

699

700

nitrogen nutrition: a global ecology scaling exercise. Annual Review of Ecology and Systematics 1994: 629-660.

43. Allen RG, Pereira LS, Raes D, Smith M. Crop evapotranspiration-Guidelines for computing crop water requirements-FAO Irrigation and drainage paper 56. FAO, Rome 1998, 300(9): D05109.

44. Kelliher F, Leuning R, Raupach M, Schulze E-D. Maximum conductances for evaporation from global vegetation types. Agricultural and Forest Meteorology 1995, 73(1): 1-16.

45. Campbell GS, Norman JM. An Introduction to Environmental Biophysics. Springer-Verlag: New York, 1998.

46. Stull RB. An Introduction to Boundary Layer Meteorology, vol. 13. Springer, 1988.

47. Ruehr NK, Martin JG, Law BE. Effects of water availability on carbon and water exchange in a young ponderosa pine forest: Above-and belowground responses. Agricultural and forest meteorology 2012, 164: 136-148.

48. Breda N, Huc R, Granier A, Dreyer E. Temperate forest trees and stands under severe drought: a review of ecophysiological responses, adaptation processes and long-term consequences. Annals of Forest Science 2006, 63(6): 625-644.

49. Clapp RB, Hornberger GM. Empirical equations for some hydraulic properties. Water Resources Research 1978, 14(4): 601-604.

50. Tyree MT, Sperry JS. Vulnerability of xylem to cavitation and embolism. Annual review of plant biology 1989, 40(1): 19-36.

51. Granier A, Loustau D, Breda N. A generic model of forest canopy conductance dependent on climate, soil water availability and leaf area index. Annals of Forest Science 2000, 57(8): 755765 .

52. Ryan MG, Yoder BJ. Hydraulic limits to tree height and tree growth. Bioscience 1997, 47(4): 235-242.

53. Jarvis PG. Interpretation of Variations in Leaf Water Potential and Stomatal Conductance Found in Canopies in Field. Philosophical Transactions of the Royal Society of London Series BBiological Sciences 1976, 273(927): 593-610.

54. Bernacchi CJ, Pimentel C, Long SP. In vivo temperature response functions of parameters required to model RuBP-limited photosynthesis. Plant Cell Environ 2003, 26(9): 1419-1430. 
701

702

703

704

705

706

707

708

709

710

711

712

713

714

715
55. Oren R, Sperry JS, Ewers BE, Pataki DE, Phillips N, Megonigal JP. Sensitivity of mean canopy stomatal conductance to vapor pressure deficit in a flooded Taxodium distichum L. forest: hydraulic and non-hydraulic effects. Oecologia 2001, 126(1): 21-29.

56. Abatzoglou JT, Brown TJ. A comparison of statistical downscaling methods suited for wildfire applications. International Journal of Climatology 2012, 32(5): 772-780.

57. Reichstein M, Falge E, Baldocchi D, Papale D, Aubinet M, Berbigier P, et al. On the separation of net ecosystem exchange into assimilation and ecosystem respiration: review and improved algorithm. Global Change Biology 2005, 11(9): 1424-1439. 